\title{
PODER Y FINANZAS EN CASTILLA EN EL TRÁNSITO A LA MODERNIDAD (UN APUNTE HISTORIOGRÁFICO)
}

\author{
DAVID ALONSO GARCÍA
}

Universidad Complutense

RESUMEN: El periodo transcurrido entre 1500 y 1525 se encuentra jalonado por algunos acontecimientos de primer orden en la historia de España, en especial, la crisis sucesoria acaecida tras el fallecimiento de Isabel I y las Comunidades de Castilla. En el presente artículo proponemos una reflexión sobre la construcción historiográfica de este período así como la influencia de esta tradición sobre las nuevas líneas de investigación. Para ello hemos optado por analizar la historiografía sobre aquellos años desde dos perspectivas: de un lado, atendiendo a las principales tendencias sobre la evolución política de la Monarquía, en un sentido amplio. Desde aquí examinamos uno de los campos donde mejor se manifestó la evolución del poder, esto es, la hacienda y el ámbito financiero. El objetivo no es tanto una recopilación total de todos los títulos aparecidos cuanto ofrecer una percepción en claroscuro del actual estado de la cuestión.

Palabras Clave: Reyes Católicos, Carlos V, historiografía, hacienda, poder financiero.

ABSTRACT: The period between 1500 and 1525 is a pivotal period in Spanish history, encompassing the dynastic crisis after Queen Isabel's death and the revolt of Comuneros. In this article we propose a rethinking of the historiographical construction of this period as well as the influence of this tradition on new lines of research. In order to achieve this objective, we will analyse the historiography of these years from two perspectives: first, we will focus broadly on the political development of the monarchy, and secondly, we will address the historiography relating to the tax system and the financial world. We will not attempt to give a full summary of all titles published, but we will offer an overview of the current state of research.

KEY WORDS: Catholic Monarchs. Charles I. Charles V. Historiography. Tax System. Financial power. 
A finales de diciembre de 1630 se redactó uno de los frecuentes memoriales que denunciaban la situación de una Castilla necesitada de referentes históricos sobre los que fundar una determinada idea de gobierno; en aquel escrito, Fernando el Católico fue presentado como un gobernante que reunía dos importantes cualidades: astucia y fuerza. De este modo, «una y otra se hallaron en el Rey don Fernando el Católico con tal extremo que se puede dudar si conquistó más con la negoçiaçión que con las armas». Con estas palabras se construía la imagen de una monarquía hábil y fuerte, negociadora y guerrera, que en realidad reproducía los ideales olivaristas de aquellos momentos ${ }^{1}$. Una década después, Gracián escribió su conocido El político don Fernando el Catbólico, obra que marca la consolidación de una visión determinada del reinado de los Reyes Católicos ${ }^{2}$. Los cronistas regios -más las dulces palabras de Castiglione y Maquiavelo- habían creado una percepción que fue tomada como fuente fundamental por Gracián y otros, lo cual, aderezado con la coyuntura política que vivía la monarquía, derivó en una proyección historiográfica caracterizada por la mitificación del período 3 . Proyección favorable encarnada en atributos de templanza, valentía y liberalidad, cualidades que pesarán (y mucho) sobre la noción historiográfica de Fernando el Católico ${ }^{4}$.

Con estas líneas no pretendemos una revisión completa y exhaustiva de todos los estudios publicados sobre una materia tan extensa como es el tránsito del medievo a la modernidad. Antes bien, nos interesa expresar algunas ideas generales que en nuestra opinión, han guiado - y guían - la percepción de aquellas décadas desde una perspectiva evolutiva. Con ello intentaremos situar el presente análisis en una perspectiva diacrónica atendiendo, por tanto, a un devenir historiográfico de varios siglos. Obviamente, no se trata de reflejar la totalidad de títulos que han ido apareciendo sobre todo lo relativo al poder y a las finanzas en los albores de la Edad Moderna, sino lanzar nuestras propias impresiones acerca de la actual producción historiográfica y las tradiciones que lo impregnan. Para ello dividiremos este trabajo en dos partes que, si bien se encuentran entrelazadas e interrelacionadas, al mismo tiempo cuentan con suficiente personalidad para ser analizadas por separado. La primera de ellas versará sobre la organización política del período final de la Edad Media y los inicios de la Modernidad, mientras que en un segundo apartado nos centraremos en diferentes aspectos de la hacienda real de Castilla de aquellas décadas.

${ }^{1}$ Este memorial se conserva en AHN, Univ., libro 1182, fols. 85 y ss. La cita se encuentra en el fol. $85 \mathrm{v}$.

${ }^{2}$ Utilizamos la versión facsímil publicada en Zaragoza, 1985.

3 TATE, R. B.: Ensayos sobre la historiografía peninsular del siglo XV, Madrid, 1970.

${ }^{4}$ Ferrari, A.: Fernando el Católico en Baltasar Gracián, Madrid, 1945. Sobre la creación de una determinada idea sobre los Reyes Católicos en el siglo XVII, CARretero Zamora, J. M.: «Representación política y procesos de legitimación", en NieTO SORIA, J. M. (Dir.): Orígenes de la Monarquía Hispánica: propaganda y legitimación (CA 1400-1520), Madrid, 1999, pp. 177-205. 


\section{A) De los Reyes Católicos a CARlos V: DOS Siglos de HiSTORIOGRAFía SOBRE EL PODER}

\section{1) A modo de introducción: el pensamiento historiográfico hasta mediados del siglo XX.}

Los Reyes Católicos han gozado de un beneplácito historiográfico que llega hasta la actualidad. Durante el siglo XIX y hasta bien entrado el siglo XX su reinado se ha interpretado a partir de tres elementos fundamentales. En primer lugar, los Reyes Católicos simbolizaban la construcción del Estado español a partir de la unidad territorial y las medidas reorganizadoras que introdujeron a lo largo de su reinado. En segundo lugar, la historiografía recogía como tema fundamental la dialéctica entre ambos monarcas dentro de la búsqueda del mayor o menor peso de Isabel y Fernando, donde la presencia de cada uno de los gobernantes simbolizaba el predominio de un modo diferente de gobierno o de un territorio determinado. Hasta el siglo XIX, Fernando disfrutó de un considerable favor historiográfico a partir de la imagen proyectada desde las décadas centrales del siglo XVII's. Sin embargo, la obra de Clemencín resultó especialmente impactante por dos motivos ${ }^{6}$. Primero, porque revalorizó la figura de la reina en relación a Fernando el Católico, y en ello se deben apreciar los vaivenes políticos acaecidos en torno al período 1808-1820. En segundo lugar, asentó la imagen del reinado en comparación con la época de Enrique y las «pérdidas de libertades» que trajeron los Austrias. La vigencia de la obra de Clemencín ha resultado sumamente duradera. La imagen de una gran Isabel I representante de las esencias castellanas podía legitimar - incluso nominalmente- la figura de Isabel II. Y lo hacía en función de unos Reyes Católicos que habían pacificado el reino, habrían instaurado el dominio de la ley y la justicia o emprendieron una dura pugna contra los privilegios nobiliarios. Dicha visión también se haya implícita en la obra de Prescott ${ }^{7}$, quien, a su vez, recogía el interés despertado por el libro de Robertson sobre el imperio de Carlos $\mathrm{V}^{8}$. En tercer lugar, la imagen de los Reyes Católicos remitía a ciertos parámetros románticos relacionados con la Inquisición, la conquista de Granada o el «descubrimiento» de América.

Éstas fueron las obras básicas que determinaron la imagen del reinado de los Reyes Católicos durante los tres primeros cuartos del siglo XIX. En cambio, al menos hasta la Restauración, la idea que se proyectaba del emperador resul-

5 Ferrari, A.: Fernando el Católico...

${ }^{6}$ Clemencín, D.: Elogio de la reina Católica doña Isabel, Madrid, 1820.

Prescott, W. H.: Historia de los Reyes Católico don Fernando y doña Isabel, México, D. F., 1952 ( $1^{\text {a }}$ ed., Londres, 1838). Sobre la influencia de Prescott en el hispanismo norteamericano, KAGAN, R.: «El paradigma de Prescott: la historiografía norteamericana y la decadencia de España», en Manuscrits, $n^{\circ} 16$ (1998), pp. 229-253.

8 ROBERTSON, W.: History of the Emperor Charles V, London, 1769. 3 vols. 
taba sumamente negativa, cuando no ignorada9. De hecho, la edición de la Historia de la vida y bechos del emperador Carlos $V$ de Sandoval en 1846-1847 constituyó una excepción al escaso interés que despertaba Carlos de Gante. La revuelta comunera había sido el último arrebato de oposición castellana, nacional, a la imposición tiránica de un emperador extraño que quebraba el desarrollo de una pretendida nación española. Las obras de Ferrer del Río, Martínez de la Rosa o Modesto Lafuente, entre otras, se escribieron en este sentido; y con ello nacía una tradición historiográfica liberal sobre las Comunidades que todavía hoy está presente en diversos estudios ${ }^{10}$. A su vez, arrancaba otra tendencia mucho más sutil pero no menos importante: la interpretación de las primeras décadas del siglo XVI en función del movimiento comunero, de tal modo que la evolución de Castilla desde la muerte de Isabel la Católica venía determinada por lo acaecido en 1520-1522. Esta visión tenía otra consecuencia añadida: la elevación del movimiento comunero a categoría de hito histórico en función de una interpretación determinada, presuponiendo que dicho acontecimiento constituía uno de los episodios fundamentales de la historia de España. De este modo comenzó una tendencia que llega hasta nuestros días, lo que ha posibilitado que Comunidades y Germanías hayan actuado de «embudo» dentro de una especie de dirigismo donde las alteraciones de 1520-1522 pueden llegar a presentarse casi como inevitables. La publicación de la crónica de Alcocer fue uno de los primeros resultados de esta afirmación ${ }^{11}$.

A partir del último tercio del siglo XIX se asistió a una serie de cambios historiográficos que resultaron fundamentales. Por un lado, la historiografía canovista varió la interpretación general de Carlos V; del rey extranjero y opresor se pasó a un monarca virtuoso que encarnaba valores nacionales entendidos en función de la religión y el Estado. En consonancia con ello, las Comunidades comenzaron a ser vistas como un movimiento contra la modernidad encarnada por Carlos V, de tal modo que la positiva imagen que se había proyectado durante los primeros sesenta o setenta años experimentó una profunda revisión. La obra de Dánvila se situaría en esta línea ${ }^{12}$. No es que los estudios sobre el Emperador experimentaran un auge desconocido, sino que la visión oficial sobre su reinado cambió por completo en función del nuevo marco político de la

9 PeIró Martín, I.: «La fortuna del emperador: la imagen de Carlos V entre los españoles del siglo XIX», en Martínez Millán, J.; ReYero, C. (Coords.): El siglo de Carlos V y Felipe II. La construcción de los mitos en el siglo XIX, vol. II, Madrid, 2000, pp. 153-194.

${ }^{10}$ Sobre ello remitimos a GUTIÉRREZ NiETO, J. I.: Las Comunidades como movimiento antiseñorial, Barcelona, 1973, pp. 19-122; PÉreZ, J.: «Las Comunidades de Castilla», en BELENGUER CeBriá, E. (Coord.): De la unión de coronas al Imperio de Carlos V, Madrid, 2001, pp. 241-257.

11 AlCOCER, P. de: Relación de algunas cosas que pasaron en estos Reinos desde que murió la Reina Católica doña Isabel, hasta que acabaron las Comunidades en la ciudad de Toledo, Sevilla, 1872.

12 DÁnVILA, M.: El poder civil en España, 6 vols. Madrid, 1885; Historia crítica y documentada de las Comunidades de Castilla, 6 vols. Madrid, 1897-1899. 
Restauración ${ }^{13}$. Al mismo tiempo, la historiografía europea comenzó a prestar una mayor atención al período carolino. Naturalmente, la Alemania bismarkiana precisaba de referentes históricos sobre los que apoyar el nuevo estado alemán, acontecimiento que no fue ajeno al nacimiento de la Historia como disciplina científica. Nada tiene de inocente el interés del positivismo germano -representado en primer lugar por L. von Ranke- en el imperio de Carlos V. Este interés, en cambio, no nació en 1870 sino que recogía la tradición de importantes recopilaciones documentales como la de K. Lanz ${ }^{14}$ o Gachard ${ }^{15}$. También es destacable que en Francia, a finales del siglo XIX y principios del siglo XIX, se desarrollara un cierto interés por el período con autores como Morel-Fatio ${ }^{16}$. En nuestra opinión, la obra de Morel-Fatio contaba con un precedente inequívoco en el estudio de $\mathrm{J}$. Mariéjol ${ }^{17}$, quien realizó un meritorio escrito sobre las instituciones y la sociedad de finales del siglo XV.

La recepción de estas obras en España fue tardía y, en parte, parcial ${ }^{18}$. Ahora bien, las numerosas publicaciones hispanas o extranjeras habían incorporado definitivamente a Carlos V a la historia de España. A principios del siglo XX topamos con autores tan relevantes como F. Fita, Rodríguez Villa, C. Espejo o F. Laiglesia que dedicarían buena parte de sus estudios al siglo XVI, y en particular al reinado de Carlos V. Los dos primeros desde la publicación de fuentes tan conocidas como las cartas de Martín de Salinas, en este caso por parte de Rodríguez Villa. La edición de la correspondencia de Gutierre Gómez de Fuensalida fue un buen síntoma del despertar historiográfico sobre las primeras décadas del siglo $\mathrm{XVI}^{19}$. F. Laiglesia y C. Espejo, por su parte, inauguraron la moderna historiografía fiscal hispana a partir de sus estudios sobre la hacienda del Emperador, como veremos más adelante.

Por último, la historiografía decimonónica sobre el período se completó con otros dos elementos importantes. De un lado, se excluyó a la reina Juana de la historiografía formal para encajonarla, fundamentalmente, en el ámbito de la literatura. Su locura y su amor por un príncipe flamenco servían de catalizador para la escritura de libros como el de F. J. de Orellana ${ }^{20}$. En cambio, la

13 PEIRÓ MARTÍN, I.: «La fortuna...».

${ }^{14}$ LANZ, K. (Edit.): Correspondenz des Kaisers Karl V aus dem Königlichen Archiv und der Bibliotéque de Bougnoge zu Brüssel, Leipzig, 1844.

15 GACHARD, L. P.: Correspondance de Charles-Quint et d'Adrien VI, Bruselas, 1859.

16 Morel-Fatio, A.: Historiographie de Charles-Quint. Premiere partie survie des Mémoires de Charles-Quint, París, 1913. Sobre la influencia de este autor en la historiografía hispana, PEIRÓ MARTÍN, I.: «La fortuna...»

17 MariéJOL, J. H.: L'Espagne sous Ferdinand et Isabelle. Le gouvernment, les Institutions et les Moeurs, París, 1892.

18 PEIRÓ MARTÍN, I.: «La fortuna...».

19 DuQue De Berwick y De AlBA: Correspondencia de Gutierre Gómez de Fuensalida, Madrid, 1907.

20 Orellana, F. J. de: La Reina loca de amor. Historia romántica de Doña Juana de Castilla y don Felipe el Hermoso, Barcelona, 1854. Sobre la imagen de doña Juana en la historiografía, ARAM, B.: La reina Juana. Gobierno, piedad y dinastía, Madrid, 2001, pp. 13 y ss. 
imagen de Cisneros resulta algo más compleja en su análisis ya que contaba con una tradición historiográfica propia; los inicios del proceso de beatificación sobre Cisneros en el siglo XVII se acompañaron de una labor de búsqueda de documentos plasmada en la célebre obra de Quintanilla ${ }^{21}$. No es difícil imaginar que la imagen del Cardenal propagaba sus cristianas virtudes en un intento fortalecer los argumentos para la beatificación ${ }^{22}$. Esta proyección, además, se plasmó en libros como el del obispo de Nimes ${ }^{23}$. En cambio, Cisneros fue relegado a un cierto olvido durante le siglo XVIII, lo que no evitaría que existiera un poso cultural que resultaría trascendental en la centuria siguiente. En concreto, este sustrato, traducido a la figura de un Cardenal piadoso, dotó de sentido a las sucesivas recopilaciones de cartas efectuadas por Gayangos y Vicente de la Fuente 24 ; en este último caso, su puesto de secretario de la Academia de Jurisprudencia le permitió acceder a los documentos cisnerianos en relación a la búsqueda de restos del Cardenal, cuestión que en aquellos momentos había tomado un especial auge 25 . Por otro lado, no resultó casual que Gayangos se interesara por el siglo XVI dada su amistad con Prescott a partir de los cargos desempeñados por aquél en Londres ${ }^{26}$, lo cual tendría una aportación fundamental en los orígenes de la historiografía hispana de la primera Edad Moderna: la publicación por parte de Gayangos de catálogos y colecciones documentales que aún hoy siguen siendo de gran valor para el investigador ${ }^{27}$. Volviendo al papel de Cisneros en la historiografía, la publicación de una parte de su correspondencia había creado la base para las dos obras que asentaron definitivamente la imagen que hoy poseemos del Cardenal; nos referimos a los escritos de Retana y del Conde de Cedillo, ambos publicados durante la dictadura de Primo de Rivera, que todavía hoy continúan siendo referentes indispensables sobre el período ${ }^{28}$.

${ }^{21}$ Archetypo de virtvdes, espexo de prelados. El venerable padre, y siervo de Dios F. Francisco Ximénez de Cisneros, Palermo, 1653.

22 Rodríguez-Moñino Soriano, R.: El cardenal Cisneros y la España del siglo XVII, Valencia, 1978.

${ }^{23}$ EsPrit Flechier, Obispo de Nimes: Historia del Cardenal don Francisco Ximénez de Cisneros, Zaragoza, 1696.

${ }^{24}$ Gayangos, P. de; Fuente, V. de la: Cartas del Cardenal don Fray Francisco Jiménez de Cisneros dirigidas a don Diego López de Ayala, Madrid, 1867. FuenTE, V. de la: Cartas de los secretarios del Cardenal D. Fray Francisco Jiménez de Cisneros durante la regencia en los años 1516 y 1517, Madrid, 1875.

${ }_{25}$ Marchamalo Sánchez, A.; Marchamalo Main, M.: El sepulcro del Cardenal Cisneros, Alcalá de Henares, 1985.

26 Peiró Martín, I.; Pasamar, G.: Historiadores españoles contemporáneos, Madrid, 2002, p. 293.

27 Para las tres primeras décadas del siglo XVI, Calendar, of Letters, Despatches and State Papers, relating the Negotiations between England and Spain, Londres, 1862-1866; Catalogue of the manuscripts in the Spanish Language in the British Museum, Londres, 1875-1893.

${ }^{28}$ FERnÁNDEZ De ReTANA, L.: Cisneros y su siglo. Estudio histórico de la vida y actuación pública del Cardenal D. Fr. Francisco Ximénez de Cisneros, 2. vols. Madrid, 1929; Cedillo, Conde de: El Cardenal Cisneros, gobernador del Reino, 3 vols., Madrid, 1921-1928. 


\section{2) El despertar historiográfico}

A la altura de 1930-1940, con la influencia del pensamiento decimonónico, el período se definía por el diferente talante — positivo o negativo - atribuido a Carlos V y comuneros, mientras que todos los estudios coincidían en señalar el reinado de los Reyes Católicos como un momento culminante en la creación del Estado español. La historiografía franquista de los años cuarenta y cincuenta aprovechó este poso cultural para reivindicar aún más la figura de Fernando como artífice de la unidad de España a partir de la creación de un Estado centralizado. En este sentido, se fortaleció la imagen de un Fernando como rey poderoso, nacional, dentro de un intento más que evidente de dotar de cierta legitimidad al régimen ${ }^{29}$; un buen rey, elevado a representante del carácter patrio, tuvo como máximo enemigo al infiel en unos conflictos que parecían antes cruzadas que guerras. Así, la historiografía nos legó títulos fundamentales - con gran cantidad de documentos transcritos - a partir de las obras de R. del Arco ${ }^{30}$, Doussinague ${ }^{31}$, Rumeu de Armas ${ }^{32}$, Cepeda Adán ${ }^{33}$ y el Barón de Terrateig ${ }^{34}$. Dichos libros se revelaron como muy importantes para el período comprendido entre la muerte de Isabel I y el advenimiento de Carlos V ya que, indirectamente, comenzaron a reivindicarlo a partir del análisis de la política exterior de Fernando el Católico. Este hecho, en nuestra opinión, se explica desde la confluencia de tres factores: de un lado, la importancia que las crónicas otorgaron a la política dinástica de Fernando el Católico tras 1508; en segundo lugar, la construcción de la monarquía como hecho hispánico desde la historiografía conservadora supuso un precedente para que ambos reinados se pudieran entender en clave de continuidad. Finalmente, el análisis del período se efectuaba presuponiendo que Fernando el Católico actuaba como gobernante de una España unida bajo su cetro. Así, desde el recién creado CSIC, autoridades como Antonio de la Torre desplegaron una ardua actividad traducida a contribuciones ineludibles como los Documentos sobre las relaciones internacionales de los Reyes Católicos. A su vez, la inmediata posguerra también asistió a un cierto auge en las obras dedicadas al cardenal Cisneros en su perspectiva de buen gobernante cristiano, si bien aquellos estudios parecían estar más cerca de la hagiografía que de la ciencia ${ }^{35}$.

29 Pasamar Alzuria, A.: Historiografía e ideología en la postguerra española: La ruptura de la tradición liberal, Zaragoza, 1981, pp. 316 y ss.

30 ARCO, R. del: Fernando el Católico: Artífice de la España Imperial, Zaragoza, 1939.

${ }^{31}$ La política internacional de Fernando el Católico, Madrid, 1944; Fernando el Católico y el cisma de Pisa, Madrid, 1946; El testamento político de Fernando el Católico, Madrid, s. f. [1950].

32 España en el África atlántica, Madrid, 1956-1957.

33 En torno al concepto de Estado en los Reyes Católicos, Madrid, 1956.

34 Política en Italia del Rey Católico 1507-1516, Madrid, 1963.

35 RODRígueZ-MOÑINO SORIANO, R.: El cardenal Cisneros... 
Aquel renovado interés se tradujo en un importante aumento en el número de publicaciones. Además, se asistió a una reorientación interpretativa ya que la política entre la dinastía Trastámara y Austria pasó a analizarse desde parámetros de continuidad cuando, recordemos, la visión del XIX imponía una cesura en las Comunidades. Las guerras de Italia o las conquistas norteafricanas suponían una fuente de primer orden en la política del Emperador. Esta visión adquiere pleno sentido si la integramos con los intentos de Menéndez Pidal por «hispanizar» la idea imperial ante la publicación de las obras de Brandi, Rasow, Chabod y Merriman y sus debates sobre el supuesto carácter moderno o medievalizante del imperio carolino ${ }^{36}$. Y para ello no había más remedio que acudir a la figura de Fernando el Católico. Ballesteros-Beretta, por ejemplo, no dudó en apostillar el proemio de Brandi con una frase que resulta más que significativa: «el nieto de los Reyes Católicos había encontrado una España fuerte, unida, sumisa a la voluntad de su rey. Fruto era esto de la gestión excelsa de Cisneros ${ }^{37}$. Las Comunidades, en cambio, pasaron a un segundo plano de una historiografía más interesada en narrar la aventuras exteriores del rey católico.

El panorama europeo resultaba bastante más alentador. A partir de los años cincuenta y sesenta comenzó a desarrollarse una primera renovación de la historia del poder, aun siendo una corriente minoritaria respecto a los temas económicos y sociales de Annales y el marxismo británico que dominaron buena parte de aquellas décadas. El denominado paradigma estatalista comenzó a cuestionarse a partir de la recepción de las obras de O. Hintze (Historia de las formas políticas, 1929) y O. Brunner (Tierra y poder, 1939), trabajos en los que se ponía el acento en las continuidades entre el sistema político medieval y moderno. De este modo, empezaba a tomar fuerza la idea de un sistema político donde el rey -el Estado- debía convivir con diversas zonas de autonomía política $^{38}$. La traducción inmediata fue la aparición de tres trabajos claves en la interpretación de una historia política ajena —al menos en cierto sentido — al concepto Estado ${ }^{39}$. Como es bien sabido, aquí estarían los referentes historiográficos últimos de los trabajos de A. M. Hespanha, J. F. Schaub, Fernández Albaladejo o B. Clavero, junto a la influencia de ciertos pensadores posmodernos como Foucault o Bourdieu. Por supuesto, estas obras forman parte del ac-

\footnotetext{
36 Sobre este particular, Fernández Albaladejo, P.: «Imperio y administración bajo Carlos V: una reevaluación», en Hernán Cortés y su tiempo, Mérida, 1987, pp. 520-527.

${ }^{37} \mathrm{La}$ cita se encuentra en BRANDI, K.: Carlos V. Vida y fortuna de una personalidad y de un Imperio mundial, Madrid, 1943, pp. 7-8.

${ }^{38}$ Un acercamiento a todo ello en HeSPANHA, A. M.: Vísperas del Leviatán. Instituciones y poder político (Portugal, siglo XVII), Madrid, 1989, pp. 19 y ss.

39 CHABOD, F.: «Y a-t-il un Etat de la Reinaissance?», en Actes du colloque sur la Renaissance, París, 1958, pp. 57-74; Oestreich, G.: «Problemas estruturais do absolutismo europeu», en HeSPanha, A. M.: Poder e Instituçoes na Europa do Antigo Regime. Colectânea de textos, Lisboa, 1984, pp. 181-200; VICENS VIVES, J.: «Estructura administrativa estatal en los siglos XVI y XVII», en Coyuntura económica y reformismo burgués, Barcelona, 1974, pp. 99-142.
} 
tual debate historiográfico sobre la existencia o no de un Estado como forma política aplicable a la Edad Moderna; debate que, asimismo, entronca con la actual discusión en torno al carácter del absolutismo en el Antiguo Régimen ${ }^{40}$.

No nos detendremos en este asunto. Lo que si interesaría resaltar es que dos de los precursores de la renovación de la historia del poder - Chabod y Vicens Vives - eran especialistas en el período. Pues bien, Chabod calificó de «anacrónico»al Imperio de Carlos $\mathrm{V}$ por el característico particularismo que definió la agregación de sus territorios, dentro del constante empeño por comparar el sistema carolino con las nacientes monarquías ${ }^{41}$; idea que, por otro lado, también se encontraba presente en el pionero libro de Koenisgberger sobre Sicilia ${ }^{42}$. Sin embargo, el autor que causó un mayor impacto sobre la historiografía española fue Vicens Vives, especialmente porque su visión escapaba al férreo marco de la historiografía «oficial», tanto la españolizante como la tradición impuesta por la historiografía catalanista ${ }^{43}$. En 1962, Vicens Vives efectuó una dura crítica a la imagen proyectada por autores como Doussinague o el Barón de Terrateig, así como a su profusa utilización de la crónica y la descripción como método esencial de exposición ${ }^{44}$. La biografía trazada por Vicens Vives intentaba superar una historiografía excesivamente vinculada al ámbito de la narración positivista en función de la denominada política exterior, si bien esta última ocupó una parte fundamental en su obra. Sin embargo, Vicens Vives introdujo algunos matices dignos de tener en consideración: en primer lugar, procuró realizar una aproximación a la educación del príncipe con el objeto de entender su propio desarrollo psicológico. Posteriormente, se centró en la obra de gobierno del Rey Católico en Aragón, Cataluña, Mallorca y los territorios italianos. Finalmente, el libro también constituyó una novedad por la utilización de fuentes inéditas procedentes del Archivo de la Corona de Aragón.

Pero su libro aún fue más allá cuando intentó desmitificar la idea de un matrimonio, el de los Reyes Católicos, basado en un equilibrio que encarnaría el ideal de un Estado centralizado. Esta cuestión no es baladí cuando suponía un choque con algunos de los preceptos más importantes de las historiografía

${ }^{40}$ La bibliografía al respecto es amplísima y conocida, por lo que no nos parece oportuno reproducirla. En cambio, sí nos parece pertinente citar los dos últimos títulos que conocemos en torno a la cuestión: SCHAUB, J.F.: «Autour de la question absolutiste: regards croisés sur la France et l'Espagne», en Le Bulletin de la Société d'Histoire Moderne et Contemporaine, no 3-4 (2000), pp. 3-16; COSANDey, F.; Descimon, R.: L'absolutisme en France. Histoire et historiographie, París, 2002.

41 Chabod, F.: Carlos V y su imperio, México D. F., 1992, p. 114.

42 Koenisgberger, H. G.: La práctica del Imperio, Madrid, 1989 (1 ${ }^{\mathrm{a}}$ ed., Ithaca, 1969).

43 Sobre este último aspecto, PASSOLA TEJEDOR, A.: La historiografía sobre el municipio en la España Moderna, Lleida, 1997, esp. 93 y ss.

44 Vicens-Vives llegaría a señalar: «nos hallamos ahora poco menos adelantados que cuando el analista aragonés Jerónimo Zurita, a fines del siglo XVI trazó por vez primera las líneas generales de su actuación». VICENS-VIVES, J.: Historia crítica de la vida y reinado de Fernando II de Aragón, Zaragoza, 1962 . 
dominante, tanto a nivel nacional como en Cataluña ${ }^{45}$. Este hecho no sólo posee una importancia fundamental a la hora de reinterpretar la agregación de los territorios en virtud de un matrimonio. La obra de Vives transformó una historiografía aragonesa-catalana que se alejaba de lo dispuesto por las formas de hacer historia oficial, donde sólo excepciones como Maravall comenzaban a ofrecer un nuevo modo de afrontar el estudio del reinado ${ }^{46}$. Por tanto, el ámbito aragonés emprendía la búsqueda de un modelo propio del reinado de los Reyes Católicos que ha llegado hasta nosotros a partir de trabajos como los de Hillgarth, también heredero de la tradición anglosajona ${ }^{47}$, E. Salvador ${ }^{48}$ y el propio E. Belenguer ${ }^{49}$. Un eslabón fundamental de esta cadena fue C. Corona, quien desde la revista de la Universidad de Zaragoza redactó varios artículos absolutamente indispensables ya que salían de la línea general de estudio de la «política exterior» para centrarse en los antagonismos internos que sacudieron Castilla para el período $1505-1516^{50}$.

A partir de los años sesenta y setenta el estudio sobre Reyes Católicos y Carlos $\mathrm{V}$ inició una nueva andadura gracias a la incorporación de planteamientos analíticos más amplios. Los trabajos de Azcona ${ }^{51}$, J. Meseguer ${ }^{52}$, Benito Ruano ${ }^{53}$, Giménez Fernández ${ }^{54}$ o el Itinerario de Ruméu ${ }^{55}$ entre otros, abrieron

${ }^{45}$ Antonio de la Torre afirmaba que «dada la compenetración entre rey y reina y la costumbre de atender a consejos, es difícil precisar en cada ocasión si las ideas y las orientaciones se deben a uno o al otro, si son de don Fernando o de doña Isabel». TORRE Y DEL CERro, A. de la: «Fernando el Católico, gobernante», en Vida y obra de Fernando el Católico. V Congreso de Historia de la Corona de Aragón, Zaragoza, 1955, p. 19.

46 Maravall, J. A.: «El pensamiento político de Fernando el Católico», en $V$ Congreso de Historia de la Corona de Aragón, Zaragoza, 1952. Separata.

47 Hillgarth, J. N.: Los Reyes Católicos, 1474-1516, Barcelona, 1984 (1 ${ }^{\mathrm{a}}$ ed., Londres, 1978).

48 Salvador Esteban, E.: «La precaria monarquía hispánica de los Reyes Católicos: reflexiones sobre la participación de Isabel I en el gobierno aragonés», en Homenaje a José Antonio Maravall, tomo III, Madrid, 1985, pp. 315-327.

49 Belenguer CebriÁ, E.: Fernando el Católico: un monarca decisivo en las encrucijadas de su época, Barcelona, 1999.

50 Corona, C. E.: «España desde la muerte del Rey Católico hasta la llegada de Don Carlos», en Universidad, $\mathrm{n}^{\circ} 54$ (1958). Separata; «Fernando el Católico y la nobleza castellana (1506-1507), en Ibidem, $\mathrm{n}^{\circ} 58$ (1960). Separata; «Fernando el Católico, Maximiliano y la Regencia de Castilla (1508-1515)», en Ibidem, no 3-4 (1961). Separata.

${ }^{51}$ Azcona, T. de: Isabel la Católica. Estudio crítico de su vida y de su reinado, Madrid, 1993 (1 ${ }^{\text {a }}$ ed., 1964).

52 Entre otros, Meseguer Fernández, J.: «Documentos históricos diversos: II el cardenal Cisneros, Inquisidor General», en Archivo Ibero-Americano, $\mathrm{n}^{\circ}$ 153-154 (enero-junio, 1979), pp. 165205; «Relaciones del Cardenal Cisneros con su Cabildo Catedral», en V simposio Toledo Renacentista, Tomo I ( $1^{\text {a }}$ parte), Madrid, 1980, pp. 25-147; «Cartas al cardenal Cisneros, Inquisidor general, 1510-1513», en Archivo Ibero-Americano, no 171-172 (julio-diciembre, 1983), pp. 285-310.

53 Benito Ruano, E.: Toledo en el siglo XV. Vida política, Madrid, 1961.

54 Giménez Fernández, M.: El plan Cisneros-Las Casas para la reformación de las Indias. I. Bartolomé de las Casas, Delegado de Cisneros para la reformación de las Indias (1516-1517), Madrid, 1984. 
un abanico de posibilidades investigadoras que hasta ese momento no habían sido exploradas. Lo mismo cabe señalar en torno a Carlos V a partir de la monumental obra de Carande, M. Fernández Álvarez ${ }^{56}$ o Sánchez Montes ${ }^{57}$. Maravall, en 1972, publicó su Estado Moderno y mentalidad social, obra que a nuestro entender supuso un importante salto cualitativo en la inclusión de la historiografía hispana en el ámbito de las ciencias sociales. Por otro lado, en los años sesenta y setenta resurgió con fuerza el tema comunero desde una perspectiva fundamentalmente liberal cuyo referente más próximo fue el pensamiento de Azaña. Lógicamente, la aparición de aquellos trabajos en los últimos años del régimen franquista no tuvo nada de inocente, constituyéndose asimismo en los principales estudios sobre los sucesos de 1520-152258. Desde aquellos momentos, la historiografía se ha destacado por un enorme desarrollo en su producción sobre aspectos tan diversos que irían desde la renovación de ciertas biografías hasta el cuidadoso análisis de los medios de gobierno con los que contaron los Reyes Católicos y Carlos V.

\section{3) Luces y sombras en el estado actual de la investigación.}

Como ya hemos señalado, no pretendemos realizar un listado siquiera genérico de los títulos que han aparecido en los dos últimos decenios ${ }^{59}$. Antes bien, nos interesaría aportar algunas consideraciones en torno a las actuales líneas de investigación. Partamos de un elemento básico, que no por obvio debemos dejar de advertir: somos herederos de diferentes tradiciones historiográficas, propias y ajenas, y hay que ser conscientes de ello a la hora de valorar la producción actual. Abogamos, por tanto, por una honda reflexión a la hora de

55 Ruméu de Armas, A.: Itinerario de los Reyes Católicos, Madrid, 1974.

56 Además de su conocida biografía, Corpus Documental de Carlos V, Salamanca, 1973

57 SÁNCHeZ MONTES, J.: 1539. Agobios carolinos y ciudades castellanas, Granada, 1974.

58 Maravall, J. A.: Las Comunidades de Castilla. Una primera revolución moderna, Madrid, 1981 (1 ${ }^{a}$ ed., Madrid, 1963); PÉREZ, J.: La revolución de las Comunidades de Castilla (1520-1521), Madrid, 1999 ( $1^{\mathrm{a}}$ ed., 1970); GUTIÉRREZ NiETO, J. I.: Las comunidades como movimiento antiseñorial (La formación del bando realista en la guerra civil castellana de 1520-1521), Barcelona, 1973. A estos títulos tendríamos que añadir los trabajos de J. L. Bermejo Cabrero ( La gobernación del reino en las Comunidades de Castilla, en Hispania, vol. XXXIII, no 124 (1973), pp. 249-264, J.B. Owens (Rebelión, Monarquía y oligarquía murciana en la época de Carlos V, Murcia, 1980), S. Halizcer (Los comuneros de Castilla. La forja de una revolución, 1475-1521, Valladolid, 1987) y B. González Alonso («Las Comunidades de Castilla y la formación del Estado absoluto», en Sobre el Estado y la Administración en la Corona de Castilla en el Antiguo Régimen, Madrid, 1981, pp. 7-56) para completar la lista de títulos básicos sobre el movimiento comunero hasta los años noventa.

59 Para ello remitimos a LAdero QueSADA, M. A.: «Historia institucional y política de la Península Ibérica en la Edad Media (la investigación en la década de los 90)», en En la España Medieval, $\mathrm{n}^{\circ} 23$ (2000), pp. 441-481. Dentro de la serie de recopilaciones bibliográficas del CINDOC, $L a$ España de Carlos V y Felipe II, 2 vols., Madrid, 1999 y Los Reyes Católicos y su tiempo, Madrid, 2004. 
entender nuestro propio quehacer con el objetivo de discernir las luces y sombras que presenta la investigación. En este sentido, lo primero que se debe señalar es el imponente número de títulos que han aparecido siguiendo las líneas más actuales de investigación. Oligarquías, propaganda, historia de la corte, el desarrollo del aparato monárquico, la implicación de la nobleza en los esquemas de gobierno, etc. constituyen campos de estudio muy conocidos a la hora de abordar una problemática concreta. Este hecho demuestra la plena inserción de la historiografía hispana en las corrientes historiográficas internacionales, si bien se echa en falta un mayor dinamismo metodológico —innovador o crítico- en cuanto a las corrientes actuales de pensamiento historiográfico. En cualquier caso, éste no es el principal problema con el que debemos enfrentarnos los historiadores de la alta — muy alta_ Edad Moderna. El mayor obstáculo (y el mayor desafío) en el desarrollo de estudios sobre el principio del siglo XVI reside en el encuentro de una tradición medieval y una tradición modernista a la hora de abordar el análisis del período. El hiato cronológico que divide ambos período resulta artificial en la investigación; sin embargo, la tradición académica ha impuesto sendas líneas que no siempre se hallan en contacto. Dicho de otro modo, medievalistas y modernistas nos acercamos al período desde posiciones diferentes, cuando no opuestas, marcadas fundamentalmente por el desconocimiento recíproco. El resultado de todo ello, salvo excepciones, son estudios que tienden a olvidar que sobre el mismo período existen otras sensibilidades. Cierto es que existen indicios que apuntan a un acercamiento entre medievalismo y modernismo ${ }^{60}$. La división académica - ¿imperecedera? - no puede afectar a investigaciones que no atiendan, por completo, a todo lo apuntado acerca del período. A buen seguro que aquellas investigaciones que miren a unos y otros ganarán en profundidad, reflexión y complejidad.

Esta actitud resulta absolutamente fundamental a la hora de abordar el tránsito del siglo XV al XVI. En los últimos años asistimos a un renovado interés a la hora de analizar las estructuras y modos de gobierno en relación a los territorios que pasaron a formar parte de la monarquía hispánica ${ }^{61}$. También

60 Por ejemplo, podemos citar la colaboración del prof. Carretero Zamora en diversos seminarios dirigidos por el prof. Nieto Soria o la presencia del prof. Ladero en numerosos encuentros con estudiosos modernistas. Recientemente T. F. Ruiz ha llegado a señalar que «la historia del siglo XVI no puede escribirse sin asentarse firmemente en el siglo anterior, y viceversa» (Historia social de Espana, 1400-1600, Barcelona, 2002, p. 12.)

61 Entre otros, CASAlS, A.: L'Emperador $i$ els catalans. Catalunya a l'Imperi de Carles V (15161543), Barcelona, 2000, esp. 21-54; PARdo Molero, J. F.: La defensa del imperio. Carlos V, Valencia y el Mediterráneo, Madrid, 2001, pp. 33-192; FELIPO ORTS, A.: Autoritarismo monárquico y reacción municipal: la oligarquía urbana de Valencia desde Fernando el Católico a las Germanías, Valencia, 2004; Traselli, C.: Da Ferdinando il Católico a Carlo V. L'esperienza siciliana 1475-1525, Messina, 1982; HeRnANDo SÁNCHEZ, C. J.: El reino de Nápoles en el Imperio de Carlos V. La consolidación de la conquista, Madrid, 2001; «El reino de Nápoles de Fernando el Católico a Carlos V (1506-1522)», en BELenguer Cebriá, E. (Coord.): De la unión..., vol. II, pp. 205-297; Thomas, W.; Stols, E.: «La integración de Flandes en la Monarquía Hispánica», en ThOmas, W.; VerdonK, R. A. (Eds.): 
para el caso castellano hay un remozado interés en analizar todo lo acontecido durante el período. Sin embargo, al igual que en los análisis sobre el reino de Valencia, hay un acontecimiento que determina la visión que se suele dar al período: las Comunidades. Es en este punto donde la tradición muestra todo su poder de influencia. Efectivamente, desde el siglo XIX, el movimiento comunero conserva una capacidad de atracción que constituye un prisma por donde mirar todo lo acaecido durante las dos primeras décadas del siglo XVI; es decir, la interpretación general de buena parte de los acontecimientos acaecidos desde 1504 se perciben en función del posterior levantamiento. No resulta sorprendente que buena parte de la información sobre el período aparezca en obras dedicadas a las Comunidades de Castilla, de modo que la orientación general es intentar buscar las causas o precedentes de aquel episodio ${ }^{62}$. La reivindicación del papel jugado por las oligarquías en la formación de la monarquía ocupa un lugar común en los análisis de los últimos años. Para el período que nos ocupa, muchos de los estudios de las elites locales tienden hacia el análisis de los con-

Encuentros en Flandes. Relaciones e intercambios hispanoflamencos a inicios de la Edad Moderna, Lovaina, 2000, pp. 1-74.

62 Además de los títulos apuntados con anterioridad, destacaríamos los siguientes trabajos: Martínez GIL, F.: La ciudad inquieta. Toledo comunera, 1520-1522, Toledo, 1993; PORRAs ARBOLEDA, P. A.: La ciudad de Jaén y la Revolución de las Comunidades de Castilla (1500-1523), Jaén, 1993; Frutos García, $\mathrm{M}^{\mathrm{a}}$ A. de: «Política, sociedad y economía en Murcia durante el primer cuarto del siglo XVI», en 1490: en el umbral de la Modernidad. El Mediterráneo europeo y las ciudades en el tránsito de los siglos XV-XVI, vol. II, Valencia, 1994, pp. 165-180; GómeZ VozmedianO, M. F.: «La revuelta de las Comunidades en La Mancha (1519-1531)», en Chronica Nova, no 23 (1996), pp. 135169; HERnÁNDEZ FrANCO, J; JimÉNEZ AlCÁZAR, J. F.: «Estado, aristocracia y oligarquías urbanas en el Reino de Murcia. Un punto de inflexión en torno a las Comunidades de Castilla», en Chronica Nova, $\mathrm{n}^{\circ} 23$ (1996), pp. 171-187; SÁNCHEZ LEÓN, P.: Absolutismo y comunidad. Los orígenes sociales de la guerra de los comuneros de Castilla, Madrid, 1998; EDWARDS, J.: «La noblesse de Cordoue et la Rèvolte des «Comunidades de Castille», en Bandos y querellas dinásticas en España al final de la Edad Media, Madrid, 1991, pp. 135-155; Diago Hernando, M.: «Las ciudades castellanas contra Carlos I: Soria durante la revuelta de las comunidades», en Celtiberia, no 94 (2000), pp. 125-184; "Clero e ordini religiosi nella rivolta delle Comunidades di Castiglia», en FrAGNITO, G; MIEGGE, M. (Eds.): Girolamo Savonarola da Ferrara all'Europa, Firenze, 2001, pp. 397-420; Le comunidades di Castiglia (1520-1521). Una rivolta urbana contro la monarchia degli Asburgo, Milán, 2001; «El conflicto de las Comunidades en Cuenca (1520-1522)», en Chronica Nova, ${ }^{\circ} 29$ (2002), pp. 27-62; «Transformaciones en las instituciones de gobierno local de las ciudades castellanas durante la revuelta comunera (1520-1521)», en Hispania, vol. XLIII/2, nº 214 (2003), pp. 623-656; ANDÚJAR CASTillo, F.: «Las comunidades en el Reino de Murcia: la tercera voz», en Castellano, J. L.; SÁnChez-Montes, F. (Coord.): Carlos V. Europeísmo y Universalidad, Madrid, 2002. A todo ello tendríamos que añadir las diferentes aportaciones aparecidas en MARTínEZ GIL, F. (Coord.): En torno a las Comunidades de Castilla. Actas del I Congreso Internacional «Poder, conflicto y revuelta en la España de Carlos I», Cuenca, 2002. Las Comunidades también han sido interpretadas como conflicto contra lo «extranjero» en Pietsmann, H.: «El problema del «nacionalismo» en España en la Edad Media. La resistencia de Castilla contra el emperador Carlos V», en Hispania, vol. LII/1 ( $\mathrm{n}^{\circ}$ 180, 1992), pp. 83-106. 
flictos acaecidos durantes aquellos años ${ }^{63}$. Éste hecho resulta muy positivo para entender la existencia de una conflictividad precomunera que influyó decisivamente en el devenir de los acontecimientos. Sin embargo, también plantea un problema; en múltiples ocasiones existe una cierta inercia a estudiar las elites en función de una determinada interpretación de las Comunidades. Interpretación que, por lo demás, suele ser deudora de los grandes paradigmas historiográficos que arrancan en el siglo XIX (revolución versus lucha de bandos), de tal modo que se presupone que los conflictos presentan una lucha de ciudades contra el poder central o reflejan una mera pugna de bandos según la orientación interpretativa del propio movimiento comunero. Y esto ha posibilitado que el conflicto comunero se haya centrado en la lucha entre ciudades y rey, lo cual - aun siendo principal — ha dejado de lado otros entes institucionales que también jugaron un cierto papel. El ejemplo de la Universidad de Salamanca resulta harto elocuente en la visión de unos años marcados por la confusión reinante y una conflictividad que llegaba a cualquier espacio o ámbito de Casti$1 a^{64}$. En este punto no estaría de más profundizar en la comparación con otros escenarios europeos que estuvieron inmersos en procesos similares ${ }^{65}$.

La tendencia a analizar pormenorizadamente los antagonismos urbanos según estos criterios resulta plausible. Mas no debe ser única, como han demostrado algunos estudios recientes ${ }^{66}$. J. Contreras ha apuntado la necesidad de integrar los conflictos políticos, sociales y religiosos en un análisis conjunto que

${ }^{63}$ Además de la bibliografía específica sobre las Comunidades, COOPER, E.: Castillos señoriales de Castilla en los siglos XV y XVI, Madrid, 1980; MARTín Benito, J. I.; GONZÁlez RodríGueZ, R.. «Lucha de bandos y beneficios eclesiásticos en los encastillamientos de Ciudad Rodrigo (14751520)», en Studia Historica. Historia Medieval, vol. XVII (1999), pp. 263-293; CASTILlo FernáNDEZ, J.: «Conflictos y protestas populares en el Reino de Granada (1504-1521)», en CASTELlanO, J. L.; SÁnCHEZ-Montes, F. (Coords.): Carlos V. Europeísmo..., vol. IV, pp. 175-209; DiaGo HernanDO, M: «Conflictos políticos en Ávila en las décadas precomuneras», en Cuadernos Abulenses, $\mathrm{n}^{\circ} 19$ (1993), pp. 69-101; «La alta nobleza en la vida política de las ciudades castellanas en las décadas precomuneras: el ejemplo de Cuenca», en Cuadernos de Historia Moderna, $\mathrm{n}^{\circ} 15$ (1994), pp. 121-141; AsEnjo GonZÁlez, M.: «Las ciudades castellanas al inicio del reinado de Carlos V», en Studia Historica. Historia Moderna, no 21 (1999), pp. 49-115. En cambio, no son tantos nuestros conocimientos sobre la conflictividad poscomunera. Sobre este particular, además de SÁNCHEZ LEÓN, P.: Absolutismo..., pp. 240-289; FORTEA, J. I.: «Los abusos del poder: el común y el gobierno de las ciudades de Castilla tras la rebelión de las Comunidades», en ForTEA, J. I.; Gelabert, J. E.; MANTECón, T. A.: Furor et rabies. Violencia, conflicto y marginación en la Edad Moderna, Santander, 2002, pp. 183-218.

${ }^{64}$ MÖller Recondo, C.: Comuneros y Universitarios: hacia la construcción del monopolio del saber, Buenos Aires, 2004.

${ }^{65}$ En esta línea, Pelizaeus, L.: «La influencia política de las ciudades en los territorios Habsburgos a comienzos del siglo XVI», en Investigaciones Históricas. Época moderna y contemporánea, $\mathrm{n}^{\circ} 23$ (2004), pp. 31-52.

66 JARA FUENTE, J. A.: «Sobre el concejo cerrado. Asamblearismo y participación política en las ciudades castellanas de la Baja Edad Media (conflictos inter o intra-clase)», en Studia Historica. Historia Medieval, vol. 17 (1999), pp. 113-136; Concejo, poder y élites. La clase dominante de Cuenca en el siglo XV, Madrid, 2000. 
relacione las diversas aristas que formarían aquel ambiente de conflictividad ${ }^{67}$. Por otro lado, el estudio de las oligarquías también debe fijarse en campos prácticamente inexplorados para las primeras décadas del siglo XVI como podrían ser las enajenaciones o apropiaciones de bienes regios ${ }^{68}$, la conformación y articulación interna de las clientelas o la evolución de los patrimonios como elemento fundamental en las relaciones de poder de diferentes zonas geográfias, entre otros ${ }^{69}$. En este sentido, los estudios de M. Gerbet o M. Diago presentan una interesante línea de investigación sobre grupos clientelares que rebasaban el ámbito de una ciudad concreta ${ }^{70}$.

Esto nos lleva a otra cuestión. La implicación de redes sociales que articulaban el contacto entre corte y territorios supone un elemento absolutamente fundamental en el desarrollo de las monarquías modernas ${ }^{71}$. Junto a ello, contamos con un gran cantidad de títulos que reflexionan sobre el carácter y características del sistema político de los siglos XV y XVI ${ }^{72}$. También contamos con

${ }^{67}$ CONTRERAS, J.: «Conversión, riqueza y poder político. Revueltas urbanas en Castilla, s. XV», en Ribot García, L A.; Rosa, L. da: Ciudad y mundo urbano en la Época Moderna, Madrid, 1997, pp. 93-115. Un magnífico ejemplo de la complejidad de los conflictos en Yun CASALILLA, B.: Crisis de subsistencias y conflictividad social en Córdoba a principios del siglo XVI, Córdoba, 1980.

${ }^{68}$ Sobre el particular, para los siglos XVI y XVII, MARCOS MARTín, A.: «Enajenaciones por precio del patrimonio regio en los siglos XVI y XVII. Balance historiográfico y perspectivas de análisis», en Actas del VI coloquio de metodología histórica aplicada, Santiago de Compostela, 2003, pp. 419-443.

${ }^{69}$ Algunas pautas sobre las luces y sombras en el estudio de elites en SORIA MESA, E.: «Los estudios sobre las oligarquías municipales en la Castilla moderna. Un balance en claroscuro», en Manuscrits, $\mathrm{n}^{\circ} 18$ (2000), pp. 185-197. Para la época bajomedieval, MARTín CEA, J. C.; BONACHIA, J. A.: «Oligarquías y poderes concejiles en la Castilla bajomedieval: balance y perspectivas», en NARBONA, R.: Oligarquías políticas y elites económicas en las ciudades bajomedievales, Valencia, 1999, pp. 17-39.

70 GERBET, M. C.: La noblesse dans le royaume de Castille. Etude sur ses structures sociales en Estrémadure de 1454-1516, París, 1979; «Nobles et clients dans le Royaume de Castille. criados et allegados en Estrémadure dans des années 1500», en CASTEllano, J. L.; SÁnCHEZ-MonTES, F. (Coords.): Carlos V. Europeísmo..., vol. IV, pp. 337-345. En la misma línea, Diago Hernando, M.: «Los Velázquez de Cuellar, tenentes de Arévalo, en el horizonte político a fines de la Edad Media», Cuadernos Abulenses, $\mathrm{n}^{\circ} 16$ (1991), pp. 11-40. También incluiremos aquí el conocido trabajo de QUINTANILLA RASO, $\mathrm{M}^{\mathrm{a}}$ C.: «Facciones, clientelas y partidos en España en el tránsito de la Edad Media a la modernidad», en Alvarado, J. (Coord.): Poder, economía, clientelismo, Madrid, 1997, pp. 15-50. Ya para tiempos posteriores, BuRGOS EstebAn, F. M.: Los lazos del poder. Obligaciones y parentesco de una elite local castellana en los siglos XVI y XVII, Valladolid, 1994.

${ }^{71}$ Las bases teóricas de este planteamiento en MANN, M.: Las fuentes del poder social. I Una historia del poder desde los comienzos hasta 1760 d. C., Madrid, 1991, pp. 13-58. La aplicación historiográfica se puede seguir en ImízCOZ, J. $\mathrm{M}^{\mathrm{a}}$.: «Comunidad, red social y élites. Un análisis de la vertebración social en el Antiguo Régimen", en IMÍzCOZ, J. M.a.: Elites, poder y red social. Las élites del País Vasco y Navarra en la Edad Moderna, Guipúzcoa, 1996, pp. 13-50; Cfr. HernándeZ, M.: «Sobre familias, relaciones y estrategias familiares en una elite ciudadana (los regidores de Madrid, siglos XVI-XVIII), en CHACón JimÉneZ, F.; HernándeZ FranCO, J. (eds.): Familias, poderosos y oligarquías, Murcia, 2001, pp. 61-80.

${ }_{72}$ En este punto destacaríamos los siguientes títulos: MORALES MOYA, A.: «El Estado absoluto de los Reyes Católicos», en Hispania, no 129 (1975), pp. 75-119; Dios, S. de: «Sobre la génesis y los 
diversas biografías escritas desde perspectivas más amplias y complejas que nos permiten un mejor conocimiento de ciertos personajes imprescindibles ${ }^{73}$. A buen seguro que la reivindicación de la biografía como método explicativo de una época dejará magníficos resultados en el futuro. Esta perspectiva se podría combinar con unos estudios de historia política que extendieran el análisis de redes a varios espacios o instituciones ${ }^{74}$, lo cual se hace aún más necesario en un mundo, el de principios del siglo XVI, que resultó fundamental en la génesis de las estructuras políticas que caracterizaron a la monarquía hispánica ${ }^{75}$. Los últimos estudios sobre la corte de los Austrias resultan fundamentales para entender cómo el juego de clientelas definió la evolución de la monarquía ${ }^{76}$. Sin embargo, el papel de los cortesanos no se entiende totalmente sin atender a otros espacios de poder en donde se implicaban, tales como ciudades o las propias Cortes de Castilla ${ }^{77}$. Este hecho resulta aun más sorprendente cuando buena parte de los títulos europeos que han servido de guía para el análisis de las facciones cortesanas incluyen capítulos donde se aprecia a la perfección que aquellas facciones tenían su razón de ser en la capacidad de articular el territo-

caracteres del Estado absolutista en Castilla», en Studia Historica. Historia Moderna, no 3 (1985), pp. 11-46; Gracia, merced y patronazgo real. La Cámara de Castilla entre 1474 y 1530, Madrid, 1993; Monsalvo Antón, J. M.: «Poder político y aparatos de Estado en la Castilla bajomedieval. Consideraciones sobre su problemática», en Studia Historica. Historia Medieval, vol. IV, no 2 (1986), pp. 101-167; GARCía MARÍn, J. M.: La burocracia castellana bajo los Austrias, Madrid, 1986; LADERO QuesadA, M. A.: «Poder y administración en España», en El Tratado de Tordesillas y su época. Congreso Internacional de Historia, vol. I, Madrid, 1995, pp. 63-89; «Fernando II de Aragón, el Rey Católico. El Estado», en SARASA, E. (Coord.): Fernando II de Aragón. El rey Católico, Zaragoza, 1996, pp. 11-27; «Poderes públicos en la Europa medieval (Principados, Reinos y Coronas)», en Poderes públicos en la Europa medieval. XXIII Semana de Estudios medievales de Estella, Pamplona, 1997, pp. 19-68; Escudero, J. A.: «El gobierno de Carlos V hasta la muerte de Gattinara. Canciller, consejos y secretarios», en García García, B.: El Imperio de Carlos V. Procesos de agregación y conflictos, Madrid, 2000, pp. 83-96. Una revisión historiográfica en SCHAUB, J. F.: «La Peninsola Iberica ne secoli XVI e XVII: la question dello Stato», en Studi Storici, año 36 (1, 1995), pp. 9-49.

73 García Oro, J.: El cardenal Cisneros. Vida y empresas, Madrid, 1992; ArAm, B.: La reina Juana. Gobierno, piedad y dinastía, Madrid, 2001.

${ }^{74}$ CHACÓN JiméNeZ, F.: «Estructuración social y relaciones familiares en los grupos de poder castellanos en el Antiguo Régimen. Aproximación a una teoría y un método de trabajo», en CASTELlano, J. L.; Dedieu, J. P.; López-Cordón, M. Va .: La pluma, la mitra y la espada. Estudios de Historia institucional en la Edad Moderna, Madrid, 2000, pp. 355-362.

75 Sobre el período inicial de la administración carolina, aun sin compartir algunas premisas metodológicas de las que parte el autor, EsPINOSA, A.: The Formation of Habsburg Rule in Spain, 1517-1528, Arizona, Universidad de Arizona, 2003 (Tesis doctoral inédita).

${ }^{76}$ Giménez FernándeZ, M.: El plan...; Martínez Millán, J. «Las elites de poder durante el reinado de Carlos V a través de los miembros del Consejo de inquisición (1516-1558)», en Hispania, vol. XLVIII, no 168 (1988), pp. 103-167; Ibid. (Dir.), La Corte de Carlos V, Madrid, 2000.

77 Un ejemplo en relación a las redes entre la corte y las Cortes en Diago Hernando, M.: «El acceso al gobierno de las ciudades castellanas con voto en Cortes a través del patronazgo regio durante el siglo XV», en Anuario de Estudios Medievales, n 32/2 (2002), pp. 879-913. 
rio desde relaciones informales ${ }^{78}$. De este modo, existe una premisa descuidada en la actual historiografía: lo que ocurría en la corte, al menos en parte, se entendía por lo acaecido en las ciudades. Y viceversa, las políticas urbanas no sólo respondían al devenir del ámbito local. En esta carencia, a su vez, se debe apreciar la influencia de los importantes estudios sobre diferentes ciudades siguiendo un modelo que tendía a la historia total y que en buena medida se han convertido en estudios de elites. Todos ellos aportan una gran cantidad de conocimientos en lo referente a un núcleo urbano determinado, pero también se han entendido de modo privativo. La consecuencia parece clara: si por un lado contamos con importantísimas obras sobre ciudades, por otro lado echamos de menos análisis que busquen mayores pretensiones geográficas e interpretativas, a excepción de algunos trabajos citados anteriormente. De ahí que, siempre en nuestra opinión, apostemos por análisis que combinen los diferentes escenarios. Mucho de esto se halla implícito en un sugerente trabajo de Santos Burgaleta, donde, partiendo de la figura de los Maldonado, se llega a dos conclusiones fundamentales: primeramente, el constante movimiento y mudanza de los bandos y grupos clientelares en los diversos espacios de poder y, junto a ello, la importancia que adquirió la presentación que pudiera realizarse de los méritos y desméritos de las personas individuales ${ }^{79}$. A su vez, el estudio de los poderosos también plantea preguntas que no siempre se han tenido en consideración. A saber, entre otras muchas que se podrían abordar, ¿cómo ejercen el poder frente a otros sectores sociales? ¿Qué capacidad de influencia tienen estos sectores sobre un grupo concreto? ¿Cuál es la relación entre lo colectivo —el grupo, la familia o la facción-y lo individual? ¿Cómo afecta la organización institucional en la creación de una identidad determinada? ¿Cómo influye el grupo en el surgimiento de un sentimiento propio, si es que existiera? Por otro lado, también existen diversos campos sobre los que se debe insistir para profundizar en algunos aspectos tocantes a la Castilla de Carlos V. En este sentido, últimamente se ha llamado la atención sobre el activo papel que continuaron ejerciendo las instituciones del común en cuestiones relativas a fiscalidad y gobierno urbano, lo que quizás resulte axiomático para una vuelta sobre las consecuencias de las Comunidades a partir de trabajos originales que puedan incorporar nuevas ideas y documentación ${ }^{80}$.

${ }^{78}$ Kettering, S.: Patrons, Brokers, and Clients in Seventeenth-Century France, Oxford, 1986; LeVY PECK, L.: Court patronage and corruption in Early Stuart England, Londres, 1990, esp. 75-105.

79 SAntos BURGaleta, M.: «<Extensiones de poder>: una propuesta de análisis en torno a la articulación de los espacios de poder. La valía del doctor Talavera en Salamanca (1475-1521)», en Bravo LoZano, J. (Ed.): Espacios de poder: Cortes, Ciudades y Villas (S. XVI-XVIII), vol. II, Madrid, 2002, pp. 73-92.

80 FORTEA PÉREZ, J. I.: «El gobierno de las ciudades de Castilla tras la rebelión de las Comunidades», en Torre de los Lujanes, $\mathrm{n}^{\circ} 46$ (2002), pp. 39-52. 


\section{B FISCALIDAD REAL Y PODER FINANCIERO: ANÁLISIS HISTORIOGRÁFICO Y ESTADO DE LA CUESTIÓN}

Los inicios de la historiografía fiscal data de finales del Antiguo Régimen, recogiendo un interés previo por recopilar la gran cantidad de normativas fiscales dispuestas desde siglos. En el ámbito hacendístico, este interés tuvo su más importante representante en el célebre tratado de J. de la Ripia ${ }^{81}$. Pero fue en las últimas décadas del siglo XVIII cuando nació un interés propio por el estudio del pasado hacendístico de España. En aquellos años comenzó un tipo de literatura hacendística caracterizada tanto por su tamaño - hablamos de obras muy extensas - como por aportar, ante todo, un tipo de información básicamente teórica y legislativa. A partir de dichas obras, por tanto, se puede extraer buena parte del corpus legislativo que regía la ordenación formal de la Real Hacienda a partir de ordenanzas y provisiones copiadas por agregación. Estos estudios —al igual que el «manual» de Ripia— intentaban esclarecer una práctica administrativa que no se entendía desde un punto de vista histórico sino político, ya que aquellos escritos (no sólo los hacendísticos) se entendieron como un elemento fundamental para el desarrollo de una publicística legislativa harto característica del sistema político de principios del siglo XIX ${ }^{82}$.

En los años finales de la década de los ochenta del siglo XVIII apareció la voluminosa recopilación de leyes de Covarrubias, cuya presentación se relaciona con los intentos de reforma proyectadas por el conde de Lerena, lo que en definitiva demuestra que aquellos estudios se redactaron bajo circunstancias muy precisas. Más allá del peso de la obra de la Covarrubias, consideramos importante citarla ya que constituye una fuente de primer orden que, desgraciadamente, ha pasado prácticamente desapercibida para los historiadores de lo hacendístico ${ }^{83}$. Más influyente resultó la obra de Gallardo Fernández, cuyo esquema ha marcado un hito para la elaboración de investigaciones clásicas de nuestra historia fiscal ${ }^{84}$. El estudio de Gallardo se centra en la transcripción de normas relacionadas con las distintas instituciones o figuras fiscales del Antiguo Régimen. Asimismo concebía un esquema cronológico en el que apuntaba

${ }^{81}$ Práctica de la administración y cobranza de las rentas reales y visita de los ministros que se ocupan de ellas, Madrid, $1694^{2}$.

${ }^{82}$ LOREnTE SARiÑena, M.: La voz del Estado: la publicación de las normas (1810-1889), Madrid, 2001.

83 Covarrubias, J.: Código o Recopilación de Leyes de la Real Hacienda, Madrid, 1790 (sita actualmente en el Instituto de Estudios Fiscales). El borrador se encuentra en la Biblioteca Nacional de Madrid bajo la signatura mss. 7605-7615. Sobre esta obra, GIBERT, R.: «La Recopilación de Hacienda de 1790», en Hacienda Pública Española, no 55 (1978), pp. 201-207 y BERMEJO, J. L.: «Dos aproximaciones a la Hacienda del Antiguo Régimen», en Anuario de Historia del Derecho Espa$\tilde{n} 0 l, \mathrm{n}^{\circ} 62$ (1992), pp. 159-238.

${ }^{84}$ Gallardo FernándeZ, F.: Origen, progresos y estado de las rentas de la Corona de España, su gobierno y administración, 7 vols. Madrid, 1805-1808. 
a los Reyes Católicos como los organizadores generales de la Real Hacienda a partir de las ordenanzas de 1476. De nuevo, como en el caso de Covarrubias, la obra poseía un componente práctico que intentaba fijar un corpus jurídico sobre el que fundamentar la gestión hacendística ${ }^{85}$. A pesar de resultar excesivamente descriptiva, la obra de Gallardo marca los inicios de la historia fiscal española con una proyección que llega hasta nuestros días. La historiografía ha considerado el escrito de Gallardo como una fuente de primer orden y, de hecho, algunas de las interpretaciones sobre aspectos determinados (p. e. la fecha de creación del Consejo de Hacienda) se han mantenido durante decenios a partir de lo asentado por Gallardo. Este autor, como acabamos de indicar, también ha resultado fundamental en relación a la época de los Reyes Católicos ya que, junto a Clemencín, nos ha legado una imagen de administración fiscal caracterizada en términos de rectitud y orden frente al período anterior ${ }^{86}$. La declaratoria de juros, la reordenación administrativa y el consiguiente aumento de los ingresos constituirían las pruebas más visibles del nuevo orden político. $\mathrm{Y}$, de este modo, ambas obras inauguraban una determinada interpretación de la hacienda de tiempos de los Reyes Católicos donde cabe destacar la utilización de documentación procedente de Simancas por parte de Clemencín.

Estas ideas resultaron positivas para el desarrollo de los estudios sobre fiscalidad por una razón básica: asentó el análisis de la hacienda real como un factor fundamental a la hora de entender el desarrollo político y económico de finales del siglo XV y el siglo XVI. Prescott, por ejemplo, dedicó una parte significativa de su libro al análisis de la Real Hacienda ${ }^{87}$. Con ello, en el siglo XIX se asistió a la publicación de numerosas trabajos que podemos considerar como los vestigios más lejanos de la historiografía fiscal hispana ${ }^{88}$. Obras que resultaban muy formales, teóricas en cuanto a la definición de los tributos y que, por extensión, construían una determinada visión del tributo en razón del nacimiento y consolidación del Estado liberal. Nada tiene de particular, por tanto, que en algunos momentos se entrelazasen los análisis de la hacienda del Antiguo Régimen con las figuras fiscales del momento ${ }^{89}$. Sin embargo, el siglo XIX

85 Característica que también se puede vislumbrar en su Prontuario de las facultades y obligaciones de los Intendentes, subdelegados, contadores, administradores, tesoreros y demás empleados en la administración y recaudo, Madrid, 1806.

86 Clemencín, D.: Elogio..., pp 154 y ss.

87 PrescotT, W. H.: Historia de los Reyes Católicos... A. Lope Orriols, a fines del XIX, continuó con la misma tendencia al definir el reinado de los Reyes Católicos como «el primitivo origen de una reconstitución, en cierto modo sistemática, de los elementos económicos del país» (Política económica de los Reyes Católicos, Barcelona, 1894, p. 12).

88 Entre éstas destacaríamos CANGas ArgüElles, J.: Diccionario de Hacienda con aplicación a España, Madrid, 1833; Colmeiro, M.: Historia de la economía política en España, Madrid, 1965 (1 ${ }^{\mathrm{a}}$ ed., Madrid, 1863). Sobre la historiografía fiscal del siglo XIX, CALLE SÁIZ, R. La hacienda pública en España. Un análisis de la literatura financiera, Madrid, 1978, pp. 237-248 y LASARTE, J (Dir.): La Hacienda y la bibliografía de 1700 a 1845, Madrid, 1980.

89 Peñasco De la Fuente, H.: Las sisas de Madrid. Apuntes para escribir su historia, Madrid, 
también asistió a excepciones que escapaban al férreo seguidismo. En 1868, por ejemplo, se publicó un artículo pionero sobre la suspensión de pagos de 1558 utilizando las relaciones de embajadores venecianos, crónicas como la de Cabrera de Córdoba y, sobre todo, fuentes documentales procedentes del Archivo General de Simancas en un claro intento por vincular la primera «bancarrota» filipina a la retirada del subsidio por parte del Pontífice ${ }^{90}$. Nada mejor que acudir a esta construcción con el objetivo de legitimar posibles desamortizaciones de los diferentes gobiernos del sexenio. Desde un punto de vista intelectual, el artículo resulta interesante ya que transcribió cifras procedentes de documentación contable que, no han pasado desapercibidas en la historiografía actual $^{91}$.

Sin embargo, la línea general apuntaba a los esquemas trazados desde principios del siglo XIX, a lo que se sumó la posterior obra de Colmeiro. Mariéjol, por ejemplo, manifestó un claro continuismo en cuanto a la descripción de la richesse publique ${ }^{92}$. La biografía de Fuentes Arias sobre Alonso de Quintanilla ${ }^{93}$ señalaba que las características básicas de la «restauración» de la hacienda por parte de los Reyes Católicos estarían definidas por la «previsión» y el «orden»a partir de la revocación de las mercedes enriqueñas; la segunda característica del nuevo orden sería la reorganización de las Contadurías entre 1476-148094. Y, sin embargo, el estudio de Fuentes Arias también supone un referente inexcusable a la hora de abordar el análisis de la hacienda real de Castilla de aquel período por dos motivos: primeramente, por la profusa transcripción de documentos, lo que hace de este libro una fuente de primer orden. En segundo lugar, porque introducía como tema de estudio la elaboración de biografías, si bien ésta tenía un marcado carácter positivista. Este último adjetivo se puede aplicar al trabajo de J. Casán ${ }^{95}$ a la hora de acercarse a la descripción de las rentas (basado en Gallardo y Colmeiro) o los rendimientos tributarios, aun cuando introdujo ciertas primicias que merecen ser citadas: por vez primera se atendía a la unificación cronológica entre el reinado de Reyes Católicos y Carlos V desde un punto de vista hacendístico. Seguidamente, entendía que ya en tiempos

1890; CRISTÓBAl y MAÑAS, M.: La Hacienda municipal de la villa de Madrid. Estudio histórico-crítico, Madrid, 1900.

${ }^{90}$ LLOREnte, A.: «La primera crisis de Hacienda en tiempos de Felipe II», en Revista de Espa$\tilde{n} a, \mathrm{I}(1968)$, pp. 317-361.

${ }_{91}$ Ruiz Martín, F.: «Un expediente financiero entre 1560 y 1575. La hacienda de Felipe II y la Casa de la Contratación de Sevilla», en Moneda y Crédito, no 92 (1965), pp. 3-58, p. 8 (nota 29); Carlos Morales, C. J. de: El Consejo de Hacienda de Castilla, 1523-1602. Patronazgo y clientelismo en el gobierno de las finanzas reales durante el siglo XVI, Ávila, 1996, p. 76 (nota 168)

92 MARIÉJOL, J. H.: L'Espagne..., pp. 215-227.

93 Fuentes ARIAS, R.: Alfonso de Quintanilla. Contador Mayor de los Reyes Católicos, 2. vols., Oviedo, 1909.

94 Ibidem, vol. I, pp. 187-203.

95 CASÁN, J.: «La hacienda de tiempos de Isabel I y Carlos I», en Revista Contemporánea, T. CXXXIV, no 681 (1907), pp. 257-264. 
de Isabel I existía una tendencia al endeudamiento como resultado de una cierta crisis fiscal, por lo que, indirectamente, se estaba desmitificando la política hacendística llevada a cabo por los Reyes Católicos.

\section{1) Contar e interpretar: la moderna historiografía fiscal}

Las obras a las que nos estamos refiriendo mostraban un manto común basado en la importancia formal de las instituciones y la comparación de ingresos y gastos como medio para medir el importe de la deuda, tomada como claro indicador de la coyuntura o la política fiscal seguida por los reyes. Metodológicamente, predominaba un discurso positivista que tendía a la repetición de lugares comunes, lo cual no resultaba ajeno a la realidad política del momento: cuanto más se repetían las ideas sobre el tema más se afianzaba una determinada percepción. La consecuencia inmediata fue la construcción de un espacio fiscal dominado por un único poder, el del rey, alrededor del cual giraba todo lo demás. Resulta evidente que, al igual que otras corrientes historiográficas, aquellos estudios venían marcados por factores políticos e ideológicos. Durante todo el siglo XIX se había creado un verdadero poso que proyectaba una imagen de la hacienda real en virtud de los parámetros que guiaban la hacienda del nuevo Estado decimonónico. La repetición de lugares comunes, sin embargo, resultó positiva a la hora de incidir en la fiscalidad como elemento fundamental de gobierno ${ }^{96}$. Desde estos parámetros se produjo el nacimiento de la moderna historiografía fiscal española gracias, fundamentalmente, a los estudios de F. Laiglesia y C. Espejo. Ambos autores se encargaron de renovar las fuentes empleadas y los campos de estudio, lo que no evita señalar que la tradición también se encontraba presente en sus escritos. Así, las aportaciones de ambos autores no propiciaron la llegada de un nuevo clima historiográfico, sino que las novedades se introdujeron asumiendo diversas líneas de continuidad, casi por agregación, de modo que el nacimiento de la moderna historia fiscal hispana se movía en la dialéctica entre persistencia y cambio.

Francisco Laiglesia, en 1907, publicó su célebre Las rentas del Imperio en Castilla, obra donde se traza un panorama general de los distintos cargos que componían la hacienda de Castilla en el intento, nunca casual, por contabilizar el total de los ingresos. La sombra de Clemencín - como demuestra la copia de datos aportados por dicho autor - resultaba alargada. Laiglesia utilizó nuevas fuentes procedentes de Simancas. Sin embargo, su trabajo se ubicaba en la órbita de la historiografía proyectada tras 1898 en sus intentos por revitalizar la figura de un Carlos V hispanizado. La añoranza del pasado imperial se dejaba entrever en sus palabras:

${ }^{96} \mathrm{La}$ influencia se puede detectar en obras como IBARRA Y RODRÍGUEZ, E. (Dir.): Documentos de asunto económico correspondientes al reinado de los Reyes Católicos (1475-1516), Madrid, 1917. 
«[...] Carlos V no impuso tributos extraordinarios, no aumentó su cuantía más que por la eficacia de la gestión y el arriendo, y realizó sólo lo que produjo el desarrollo normal de la riqueza pública [...] Sin pechos extraordinarios, sin cargas abrumadoras, con recursos normales intervinimos con éxito en la política europea de aquellos días, dándola un carácter genuinamente español; perdidas hoy las colonias, reducida nuestra nacionalidad y sin influencia exterior, procuremos al menos, con gravámenes o sin ellos, reorganizar las fuerzas nacionales para mantener la significación histórica que entonces tuvimos, y que quizás podamos recobrar aún en el porvenir»97

Apuntemos que Laiglesia se integró en las filas del partido liberalconservador de Canovas ${ }^{98}$. El resto de sus trabajos también incorporarían la idea de presentar a un Carlos V cuya política hacendística fue positiva en todos sus aspectos dentro de un imaginario historiográfico fundado en la dialéctica prosperidad/decadencia ${ }^{99}$. La perspectiva de Laiglesia, por consiguiente, resultaba parcial e incluso presentista en la utilización de los conceptos fiscales vigentes a principios del siglo XX. Sin embargo, su obra resultó sumamente útil en cuanto a la utilización de nuevas fuentes. La transcripción de las instrucciones de Valladolid de 1523, las cuales venían a crear el Consejo de Hacienda, o de la documentación procedente de la visita efectuada por el doctor Velasco en 1554 supone un hito en la historiografía fiscal del siglo XVI ${ }^{100}$. Además, este autor inauguró uno de las temáticas de mayores posibilidades: el análisis de las plantillas que formaban las instituciones hacendísticas.

Los inicios de la moderna historiografía fiscal se vieron potenciados por la respuesta que realizó C. Espejo a dicho trabajo ${ }^{101}$. Para Espejo, en contra de Laiglesia, las instrucciones de 1523 no supusieron la creación de ninguna comisión sino la fundación del Consejo de Hacienda ${ }^{102}$. A pesar de que Espejo no advirtió las sucesivas transformaciones del Consejo entre 1523 y 1525 , su reinterpretación constituye la génesis de la actual datación dada por la historiografía en la creación del Consejo de Hacienda ${ }^{103}$ De este modo, quebraba la opi-

97 LAiglesia, F.: Las rentas del Imperio en Castilla, Madrid, 1907, p. 10.

98 Peiró Martín, I.; PAsamar, G.: Historiadores..., pp. 347-348

99 Laiglesia, F. de: «Las deudas del Imperio», en Nuestro Tiempo. Revista mensual ilustrada, $\mathrm{n}^{\circ}$ 47 (noviembre, 1904), pp. 153-228; Los gastos de la Corona en el Imperio, Madrid, 1907. En la misma línea cabe interpretar la traducción por parte de Laiglesia del importante estudio de HAËBLER, K.: Prosperidad y decadencia económica de España, Madrid, 1899 ( $1^{\text {a }}$ ed., Berlín, 1888)

${ }^{100}$ Laiglesia, F. de: «Organización de la Hacienda en la primera mitad del siglo XVI», en Estudios Históricos, T. II, Madrid, 1918, pp. 6-77.

${ }_{101}$ ESPEJO, C.: «Sobre organización de la Hacienda Española en el siglo XVI», en Cultura Española, ${ }^{\circ} 6$ (1907), pp. 402-428 y no 7 (1907), pp. 687-704.

102 Hernández Esteve, C.: Creación del Consejo de Hacienda de Castilla (1523-1525), Madrid, 1983, pp. 17-20.

103 Gelabert, J. E.: «Sobre la fundación del Consejo de Hacienda», en ForTeA PÉREZ, J. I.; CreMADES GRIÑÁN, C. M. (Edits.): Política y hacienda en el Antiguo Régimen, Murcia, 1993, pp. 83-95. 
nión mantenida por Gallardo Fernández y por toda la historiografía del siglo XIX. Asimismo, Espejo extrajo diferentes informaciones en torno a los oficiales de hacienda, lo que, en definitiva, constituye el referente último de las actuales líneas de investigación sobre la historia social de las instituciones fiscales. En esta línea, no podemos olvidar que tanto Espejo como Laiglesia han sido los primeros que han abordado la figura del oficial perteneciene a las Contadurías o al Consejo de Hacienda ${ }^{104}$, aun cuando la línea interpretativa resultara parcial o, posteriormente, se hayan detectado ciertos errores. Estos trabajos, por otro lado, entroncan con la proliferación de biografías sobre oficiales de los Reyes Católicos escritas en los años cincuenta y sesenta del siglo XX. Biografías que resultaban sumamente positivistas, pero que recogen una gran cantidad de noticias sobre el período ${ }^{105}$. Finalmente, los estudios de Cristóbal Espejo no sólo giraron en torno a la organización institucional de la Real Hacienda sino que abarcaron temas como las ferias de Medina ${ }^{106}$, la indagación sobre rentas particulares $^{107} \mathrm{o}$ el análisis de la estructura interna de ciertos encabezamientos ${ }^{108}$.

Ramón Carande escribió su célebre obra en la inmediata posguerra ${ }^{109}$. Resulta indiscutible que sus tres volúmenes constituyen la disertación más notable en torno a la hacienda de Castilla entre 1520-1556. Y no sólo en lo relativo a lo tocante al mundo financiero y fiscal de aquella Castilla, sino que su consulta continúa siendo imprescindible en cualquier estudio genérico sobre el período. Sin embargo, la magna obra de Carande también tenía sus fuentes, sus motivaciones. Más allá de la amplia utilización de fuentes primarias, debemos indicar que su trabajo no sólo incorporaba la herencia de C. Espejo y F. Laiglesia sino que integraba la utilización de diversos estudios europeos relacionados

104 EsPejO, C.: El Consejo de Hacienda durante la presidencia del Marqués de Poza, Madrid, 1924; «Biografía española. Francisco de Almaguer», en Revista Nacional de Economía, tomo XXIV, enerofebrero, 1927, pp. 469-476; y PAZ, J.: «Antonio de Fonseca, señor de Coca y Alaejos, contador mayor de Hacienda, en Revista de la Biblioteca, Archivo y Museos del Ayuntamiento de Madrid, $\mathrm{n}^{\circ} 31$ (julio, 1931), pp. 297-302.

105 Además de las biografías de Cisneros o Juana la Loca, caben destacar Comas Ros, M.: Juan López de Lazárraga, Secretario de los Reyes Católicos y el Monasterio de Vidaurreta en la villa de Oñate, Barcelona, 1936; Bullón Y Fernández, E.: El doctor Palacio Rubios y sus obras, Madrid, 1927; Maqueda, Duque de: Don Gutierre de Cárdenas. Íntimo confidente y consejero de los Reyes Católicos, Madrid, 1945; MAta Carriazo, J. de la: «Tres cortesanos de los Reyes Católicos: Gonzalo Chacón, Gutierre de Cárdenas y don Diego Hurtado de Mendoza (semblanzas ejemplares de Gonzalo Fernández de Oviedo), en Clavideño. Revista de la Asociación Internacional de Hispanismo, no 12 (noviembre-diciembre, 1951), pp. 9-12.

106 EsPejO, C.; PAZ, J.: Las antiguas ferias de Medina del Campo. Investigación histórica acerca de ellas, Valladolid, 1908.

107 ESPEJO, C.: «La renta de salinas hasta la muerte de Felipe II», en Revista de Archivos, Biblioteca y Museos, 1919 (separata); Rentas de la agüela y habices de Granada (apuntes para su estudio), Valladolid, 1918.

108 EspejO, C.: El encabezamiento de Madrid por Alcabalas, de 1547 a 1556, Madrid, 1928.

109 Carande, R.: Carlos V y sus banqueros, 3. vols, Madrid, $1990^{3}$. 
con bancos ${ }^{110}$ o mercantilismo ${ }^{111}$. El Carlos $V$ y sus banqueros demuestra el alto y creciente nivel de deuda que hubo de soportar la monarquía. En nuestra opinión, dicha interpretación posee un trasfondo ideológico en el que no se ha reparado suficientemente, y que se debe tener muy en consideración a la hora de valorar la majestuosa obra del profesor: su visión de los enormes compromisos soportados por los castellanos chocaba fundamentalmente con Francisco Laiglesia y Cristóbal Espejo. Como hemos indicado, Laiglesia se esforzó por demostrar que la política carolina no se realizó a partir de un régimen fiscal especialmente gravoso. La lectura de Carande, en cambio, indica todo lo contrario. Esto se explica desde un punto de vista político ya que, si tanto Espejo como Laiglesia escribieron desde una perspectiva liberal-conservadora, Carande se caracterizó por una afinidad netamente progresista. De hecho, Carande militó en UGT y adquirió el cargo de consejero de Estado en 1931112. Nada tiene de extraño que su obra pretendiera la desmitificación propuesta en los años anteriores, para lo cual era fundamental incidir en la gravosa deuda como resultante de un pretendido déficit fiscal. Esto, en definitiva, presentaría una imagen de Carlos V bien alejada de las posiciones conservadoras. Sin duda, la obra de Carande supone uno de los trabajos hispanos de mayor trascendencia internacional. Empero, su impresionante aparato crítico y la utilización de bibliografía prácticamente desconocida hasta ese momento ha propiciado una extraña reverencia hacia sus conclusiones. Sus datos, sus ideas, sus métodos siguen estando vigentes hasta la actualidad ${ }^{113}$. Pero no responde a la casualidad que Carande intentara construir una visión determinada donde la deuda respondía unívocamente a la idea de un gasto desmesurado, presuponiendo por tanto que constituía el recurso ante una política financiera errónea. Con ello, implícitamente, se asentaba la idea de una hacienda pública cuyo funcionamiento remitía a nuestros actuales conceptos de ingreso, gasto o deuda. Así, la magnitud de aquella obra ha influido en un doble sentido, para bien y para mal. Por un lado, con todo lo que aportaba, supone un referente indispensable que abre o consolida multitud de perspectivas de investigación. Pero, por otra parte, la misma dimensión de su obra ha impedido una mayor reflexión o acti-

110 Ehrenberg, R.: Le siècle des Fugger, París, 1955 (1 $1^{\text {a }}$ ed., 1940).

111 Heckscher, E. F.: Mercantilism, Londres, 1931. A destacar la utilización por Carande de los trabajos de J. Viner (Studies in the theory of international trade, Nueva York, 1937) en tanto que ponían en duda la existencia de una doctrina única y coherente que pudiera dotar de contenido al mercantilismo. Sobre este particular, PERDICES DE BLAS, L.; REEDER, J.: El mercantilismo: política económica y Estado nacional, Madrid, 1998, pp. 9-58.

112 Peiró Martín, I.; Pasamar, G.: Historiadores..., p. 162.

113 Como se puede apreciar en Pulido Bueno, I.: La corte, las Cortes y los mercaderes. Política imperial y desempeño de la hacienda real en la España de los Austrias, Huelva, 2002; TRACY, J. D.: Emperor Charles V, Impresario of War. Campaign Strategy, International Finance, and Domestic Politics, Cambridge, 2002. Un interesante comentario este ultimo en H. G. KOENISGBERGER The International History Review, vol. XXV, $\mathrm{n}^{\circ} 3$ (septiembre, 2003), pp. 646-648. 
tud crítica hacia sus conclusiones. Lástima que esta última consideración se haya visto desatendida.

\section{2) Nuevas perspectivas, nuevas investigaciones. Una valoración}

Además de la obra de Carande, la historiografía fiscal cuenta con otros estudios que merecen el calificativo de clásicos, aun cuando éstos escapan al marco cronológico propuesto en este estudio. Nos referimos a las obras de Domínguez Ortiz ${ }^{114}$, Ulloa ${ }^{115}$, cuyo precedente no sólo hay que situarlo en Carande sino en un pequeño y excelente artículo de Merriman ${ }^{116}$, F. Ruiz Martín ${ }^{117}$, los trabajos de Moxó sobre la alcabala ${ }^{118}$ y los diferentes estudios del prof. Ladero sobre la hacienda real en tiempos de los Reyes Católicos ${ }^{119}$. El trabajo de Carande empujó a escritos que seguían un modelo típico en la sistematización de ingresos y gastos junto al análisis de la política fiscal de cada uno de los reinados. Estas obras se caracterizaban por el análisis general de la hacienda real durante un período determinado, lo cual presuponía el estudio de la administración, los mecanismos de recaudación y el peso de la deuda. Por esta perspectiva genérica, aquellos títulos resultan fundamentales a la hora de acercarse al estudio de la hacienda, de tal modo que la historiografía fiscal cuenta con un verdadero corpus que ha servido de base fundamental a la hora de realizar una aproximación de conjunto a la historia de la Real Hacienda ${ }^{120}$. Por tanto, la

114 Domínguez Ortiz, A.: Politica y hacienda de Felipe IV, Madrid, 1983.

115 UlloA, M.: La hacienda real de Castilla en el reinado de Felipe II, Roma, 1963.

116 Merriman, R. B.: «A note of the finances of Philiph II», en Revue Hispanique, vol. 81, (II, 1933), pp. 30-84.

117 Ruiz Martín, F.: «Las finanzas españolas durante el reinado de Felipe II», en Cuadernos de Historia. Anexo de Hispania, no 2 (1968), pp. 109-173.

118 Moxó, S. de: La alcabala. Sobre sus orígenes, concepto y naturaleza, Madrid, 1963; «Los cuadernos de alcabalas. Orígenes de la legislación tributaria castellana», en Anuario de Historia del Derecho Español, tomo XXXIX (1969), pp. 317-450. Esta línea ha sido continuada por GARCíA-MARGALLO RIAZA, M.: «De la alcabala medieval a los actuales impuestos sobre ventas y servicios: un cauce histórico», en Hacienda Pública Española, no 69 (1981), pp. 91-105; IGLESIAS SuÁreZ, A.: «La alcabala (una aproximación al estudio histórico de la tributación indirecta en la España del Antiguo Régimen)», en Homenaje al profesor Alfonso Otero, Santiago de Compostela, 1981, pp. 537-551. Desde una perspectiva bien diferente, PARDOS, J. A.: «La renta de alcabala vieja, portazgo y barra... del concejo de Burgos durante el siglo XV (1429-1503)", en Historia de la Hacienda Española (épocas antigua y medieval). Homenaje al Profesor García de Valdeavellano, Madrid, 1982, pp. 609-680.

119 LADERO QueSADA, M. A.: «La hacienda real castellana entre 1480 y 1492», en Estudio y Documentos, $\mathrm{n}^{\circ} 26$ (1967). Separata; La Hacienda Real de Castilla en el siglo XV, La Laguna, 1973; «La Hacienda Real de Castilla en 1504. Rentas y gastos de la Corona al morir Isabel I», en Historia. Instituciones. Documentos, $\mathrm{n}^{\circ}$ (1976), pp. 3-37. El siglo XV en Castilla. Fuentes de renta y política fiscal, Barcelona, 1982.

120 Artola, M.: La hacienda del Antiguo Régimen, Madrid, 1982; Garzón Pareja, M.: Historia de la Hacienda de España, 2 vols., Madrid, 1984. Como aproximaciones recientes a la evolución de la 
tradición historiográfica hispana conserva la existencia de estudios por reinados que suponen libros fundamentales tanto para la hacienda en general como para un período determinado ${ }^{121}$.

A partir de los años sesenta y, sobre todo, en las décadas de los ochenta y noventa la historiografía fiscal ha experimentado un auge importantísimo. Los temas a investigar y las fuentes utilizadas se han diversificado, así como los puntos de vista adoptados en los estudios ${ }^{122}$. Esto se ha plasmado en diversas reuniones, congresos o seminarios que demuestran la vitalidad del tema. Este vigor, además de la existencia de un basamento anterior, está conectada con la renovación de la historia económica ${ }^{123}$, a lo que habríamos de sumar la incorporación de la historiografía hispana a las líneas de investigación internacionales, aunque ésta haya llegado tardíamente ${ }^{124}$.

Desde aquí se ha desarrollado con fuerza la renovación de los estudios sobre instituciones y elites de poder en torno a la fiscalidad. Es sabido que los actuales estudios de historia fiscal han revalorizado el concepto de negociación a la hora de analizar las relaciones entre gobernantes y gobernados ${ }^{125}$. Este campo, en principio, viene a complicarse por la indefinición de los límites entre casas reales y oficios «públicos», lo cual también afecta a un plano hacendístico ${ }^{126}$.

fiscalidad de los siglos XVI-XVIII podemos destacar GELABERT, J. E.: «Castile, 1504-1808», en BONNEY, R.: (Edit.): The rise of the Fiscal State in Europe c. 1200-1815, Oxford, 1999, pp. 201-241. Desde perspectivas que superan lo estrictamente fiscal, MARCOS MARTíN, A.: España en los siglos XVI, XVII y XVIII: economía y sociedad, Barcelona, 2000; Yun CASAlILla, B.: Marte contra Miverva. El precio del imperio español c. 1450-1600, Barcelona, 2004. Asimismo, y aun tratando fundamentalmente de la época contemporánea, nos gustaría destacar los preceptos teóricos de los que parte Comín, F.: Historia de la Hacienda Pública, 2 vols., Barcelona, 1996.

${ }^{121}$ Lo cual llega hasta la actualidad. Cfr. SÁnCHEz BeLÉn, J. A.: La política fiscal en Castilla durante el reinado de Carlos II, Madrid, 1996; GELABERT, J. E.: La bolsa del rey. Rey, reino y fisco en Castilla (1598-1648), Barcelona, 1997.

122 HernÁNDEZ, B.: «Finanzas y hacienda en los territorios de la monarquía hispánica. Revista de una década historiográfica, 1988-988», en «Tirar con pólvora del rey» o el dinero de todos (Estudios de hacienda y fiscalidad en la España Moderna. Monográfico de Cuadernos de Historia Moderna, $\mathrm{n}^{\circ} 21$ (1998), pp. 267-326. Una visión más crítica del actual estado de la cuestión en REY CASTELAO, O.: «Los estudios sobre fiscalidad en la época moderna: fenómeno historiográfico real o aparente?», en Obradoiro de Historia Moderna, $\mathrm{n}^{\circ} 13$ (2004), pp. 215-252.

123 Musgrave, P.: The Early Modern European Economy, New York, 1999, esp. 1-12.

${ }^{124}$ Las actuales líneas de investigación en historia fiscal se pueden seguir a partir de TRACY, J. D.: «Taxation and State Debt», en BRADY, T. A. et alii: Handbook of European History. Late Middle Ages, Renaissance and Reformantion, vol. I, Leiden-New York, 1994, pp. 563-588. En nuestra opinión, las aportaciones más significativas a nivel internacional son BONNEY, R. (Dir.), Systèmes èconomiques et finances publiques, París, 1996 y The Rise of the Fiscal State in Europe c. 1200-1815, Oxford. 1999.

125 DubET, A.: «Finances et réformes financières dans la monarchie espagnole», en Le bulletin de la S.H.M.C, $\mathrm{n}^{\circ}$ 3-4 (2000), pp. 56-83.

126 Un buen ejemplo de las implicaciones económicas de la financiación «doméstica» del rey en REDWORTH, W.: «Philiph I of England, embezzlement, and the quantity theory of money», en The Economic History Review, vol. LV, (2, 2002), pp. 248-261. 
Así, la financiación de las casas reales ha sido objeto de atención en los últimos años $^{127}$, aun cuando existen temas en los que se debe insistir como la relación entre estas casas — su personal- con la administración del rey, reino o los grupos financieros. De este modo, sin duda, la institución más estudiada es el Consejo de Hacienda, gracias a lo cual conocemos en profundidad su estructura y atribuciones institucionales, incluida la transcripción y análisis de ordenanzas o instrucciones ${ }^{128}$. Esta visión, por tanto, nos proporciona una imagen fiel de la evolución teórica del organismo, mas tiene el problema de haber dejado a un lado al personal que conformaba el Consejo de Hacienda. Los recientes trabajos de C. J. de Carlos suponen una interesante perspectiva sobre la formación y evolución de los grupos en relación a las facciones cortesanas ${ }^{129}$. Sin embargo, uno de los problemas que plantea el estudio del gobierno del fisco reside en la multitud de organismos (Consejos, contadurías, juntas, etc.) que entendían en dicho aspecto, lo que implica que la visión del Consejo — desde un punto de vista institucional y sociológico- se debe completar con un análisis de otros organismos. Y justo en este aspecto nos encontramos con graves lagunas. Sin entrar en el papel de organismos como el Consejo de Guerra, Indias, Estado o Castilla, podemos considerar que el análisis de los otros organismos directamente encargados de la real hacienda continúa en mantillas. Conocemos la organización interna y atribuciones teóricas de las Contadurías Mayores a partir de ordenanzas e instrucciones, especialmente en el caso de la Contaduría Mayor de Hacienda ${ }^{130}$. Sin embargo, el nivel de conocimientos sobre el perso-

127 Romani, M. A.; Aymard, M.: «La cour comme institution economique», en NúÑEZ, C. E. (Ed.): Debates and Controversies in Economic History Proceeding Twelfth International History Congress, Madrid, 1998, pp. 145-17. Para el caso español, JuRAdo SÁNCHEZ, J.: El gasto de la casa real, su financiación y sus repercusiones hacendísticas y económicas, Madrid, 2001.

${ }^{128}$ Hernández Esteve, E.: Creación...; «Estructuras y atribuciones del Consejo de Hacienda durante su proceso constituyente», en Cuadernos de Investigación Histórica, no 8 (1984), pp. 35-64; García-CuencA, T.: «El Consejo de Hacienda (1576-1803)», en ARTOLA, M. (Edit.): La economía española al final del Antiguo Régimen. IV. Instituciones, Madrid, 1982, pp. 405-502; CUARTAS RIVERO, M.: el Consejo de Hacienda: su primera época», en Hacienda Pública Española, no 74 (1982), pp. 255-266. Pérez Bustamante, R.: «Del sistema de contadurías al Consejo de Hacienda, 14331525 (una perspectiva institucional), en Historia de la Hacienda Española (épocas antigua y medieval), Madrid, 1982, pp. 681-738; HeRAS, J. L. de las: «La jurisdicción del Consejo de Hacienda en tiempos de los Austrias», en CREMAdes Griñán, M. C. (Edit.): Estado y fiscalidad en el Antiguo Régimen, Murcia, 1989, pp. 117-127; GELABERT, J. E.: «Sobre la fundación...».

129 Carlos Morales, C. J. de: «El Consejo de Hacienda de Castilla en el reinado de Carlos V (1523-1556)», en Anuario de Historia del Derecho Español, $\mathrm{n}^{\circ} 69$ (1989), pp. 49-159; El Consejo de Hacienda...

130 Además de los títulos señalados anteriormente para el Consejo de Hacienda, HeRnÁNDEZ ESTEVE, E.: Contribución al estudio de las Ordenanzas de los Reyes Católicos sobre la Contaduría Mayor de Hacienda y su oficio, Madrid, 1988; «Las contadurías de libros de la Contaduría Mayor de Hacienda a mediados del siglo XVI», en Revista de Contabilidad, vol. 1, no 1 (enero-junio, 1998), pp. 103-135. GIBERT, R.: "Contadores de Hacienda e intervención fiscal en el Antiguo Régimen castellano», en Itinerario histórico de la Intervención General del Estado, Madrid, 1976, pp. 91-143. 
nal que los integraba continúa siendo muy elemental, incluidos personajes tan importantes como los contadores mayores ${ }^{131}$. Menos, incluso, sabemos de la Contaduría Mayor de Cuentas, donde el trabajo pionero de R. Mendizábal continúa siendo insustituible ${ }^{132}$. En este sentido, se puede apreciar la larga sombra de Gallardo Fernández habida cuenta del mínimo espacio que reservó a la Contaduría de Cuentas; laguna que también se puede detectar en las obras de C. Espejo y F. Laiglesia. El resultado de este «olvido» no es otro que la imagen de un régimen de Contadurías jerarquizadas donde el organismo de gestión parece contar con varios cuerpos de ventaja sobre el de fiscalización. De este modo, la Contaduría de Cuentas está por estudiar tanto en su vertiente institucional como sociológica ya que poco sabemos sobre los procedimientos administrativos que definían una labor tan importante como la fiscalización de los oficios hacendísticos. Este aspecto resulta especialmente insólito cuando la Contaduría Mayor de Cuentas ha dejado un vasto volumen de documentación en Simancas ${ }^{133}$. La conclusión es obvia: aún queda mucho por explorar en relación a ambas instituciones acerca de cuestiones relativas al trámite administrativo, la articulación interna — no sólo teórica — de las Contadurías o los mecanismos de transmisión de información entre los diferentes organismos. En este sentido, los recientes trabajos de A. Romero constituyen un avance importante sobre el trámite interno de las Contadurías ${ }^{134}$. A su vez, existen temas puntuales que se vienen investigando con gran vigor. Por ejemplo, el fraude y la corrupción se encuentran en fase de profunda reinterpretación ${ }^{135}$, cuestión que, por lo demás, se encuentra íntima-

131 En este sentido se debe acudir a los trabajos de Espejo y Laiglesia para encontrar información en torno al personal de esta Contaduría. También el reciente estudio sobre la Corte de Carlos V dirigido por Martínez Millán incluye numerosos datos al respecto. Sin embargo, escasean los trabajos monográficos, entre los que cabe destacar, Diago Hernando, M.: «Los Velázquez de Cuéllar...»

132 Mendizábal Allende, R.: «La Contaduría Mayor de Cuentas», en Revista de derecho judicial, no 25 (enero-marzo, 1966), pp. 11-35. Posteriormente, HeRnándEz ESTEVE, E.: «La Contaduría Mayor de Cuentas de Castilla en tiempos de los Reyes Católicos (1474-1515)», en Doctor Goznes Duch. La imagen fiel, Barcelona, 1997, pp. 95-133.

133 Un ejemplo de las posibilidades de esta sección en ANDRÉs DíAZ, R. de: El último decenio del reinado de Isabel I a través de la tesorería de Alonso de Morales (1495-1504), Valladolid, 2004. Una excepción en cuanto a estudio del personal que ocupaba la contaduría de cuentas, CARLOS MORALES, C. J.: «Los medios de control contable de las finanzas en tiempos de Felipe II: el teniente Francisco Gutiérrez de Cuéllar y la Contaduría Mayor de Cuentas (1560-1579)», en MARTíNEZ MiLLÁN, J. (Dir.): Felipe II (1527-1598). Europa y la Monarquía Católica, vol. II, Madrid, 1998, pp. 165-196.

${ }^{134}$ Romero Martínez, A.: Los papeles del fisco. Estudio diplomático de la documentación fiscal castellana bajomedieval, Granada, 1998; Fisco y recaudación. Impuestos directos y sistemas de cobro de la Castilla medieval, Granada, 1999.

135 Entre otros, FORTEA PÉreZ, J. I.: «Aproximación al estudio de las actitudes sociales ante el fisco: el fraude fiscal en la Corona de Castilla en el siglo XVII», en Studia Historica. Historia Moderna, $\mathrm{n}^{\circ} 5$ (1987), pp. 99-110; FONTANA, J.: «Las reglas y el juego. Algunas reflexiones históricas sobre la corrupción», en El fraude fiscal en la Historia de España. Monográfico de Hacienda Pública Española, no 1 (1994), pp. 25-29; YUN CASALILlA, B.: «Corrupción, fraude, eficacia hacendística y economía en la España del siglo XVII», en Ibidem, pp. 47-60; CÁRCELES DE GEA, B.: Fraude y desobe- 
mente relacionada con los manejos e intereses a los que daba lugar la administración militar, como magníficamente ha expuesto A. Esteban para el primer tercio del siglo XVII en clara conexión con las la temática estudiada por Parker y Thompson ${ }^{136}$. Este campo resulta menos estudiado para las primeras décadas del siglo XVI, aun cuando existe un precedente historiográfico que no debe caer en el olvido ${ }^{137}$.

Por otro lado, empezamos a ser conscientes de las diferentes vertientes que encarnaba una figura fundamental de aquellos esquemas fiscales: los tesoreros generales. En principio, como en otras ocasiones, el análisis de este cargo resultó meramente formal a partir del estudio de ordenanzas e instrucciones a partir de una perspectiva determinada: observar la tesorería en conexión con una mayor o menor unidad de caja ${ }^{138}$. Sin embargo, la estrecha vinculación entre tesoreros y crédito sin atender a los parámetros de público/privado ha potenciado el paso del estudio de la tesorería al de los tesoreros, en lo que también se debe apreciar la influencia de transcripciones documentales sobradamente conocidas ${ }^{139}$. Así, contamos con trabajos monográficos sobre Francisco de Vargas ${ }^{140}$, Adurza ${ }^{141}$, Alonso de Morales ${ }^{142}$, Melchor de Herrera $^{143}$, Juan Fernández Espinosa ${ }^{144}$, Luis de Santángel ${ }^{145}$ o Rodrigo de Due-

diencia fiscal en la corona de Castilla, 1621-1700, Valladolid, 2000; Alonso GARCíA, D.: «¿Pagar o no pagar? En torno al fraude fiscal eclesiástico en el Antiguo Régimen», en Cuadernos de Historia de España, T. LXVIII (2001-2002), pp. 187-206.

136 Esteban Estríngana, A.: Guerra y finanzas en los Países Bajos católicos. De Farnesio a Spínola (1592-1630), Madrid, 2002.

137 STEWART, P.: «The soldier, the Bureaurcrat, and Fiscal Records in the Army of Ferdinand and Isabella», en The Hispanic American Historical Review, vol. 49 ( $\mathrm{n}^{\circ}$ 2, 1969), pp. 281-292.

138 CuArtas Rivero, M.: «Los tesoreros generales de la Corona de Castila en el siglo XVI (Orígenes de la Dirección General del Tesoro)», en Presupuesto y gasto público, no 9 (1981), pp. 77-93.

139 Torre, A. de la (Ed.): Cuentas de Gonzalo de Baeza, tesorero de Isabel la Católica, Madrid, 1956; Libro Mayor del «Banquero de Corte» de los Reyes Católicos Ochoa Pérez de Salinas (1498-1500). Estudio preliminar por F. Ruiz Martín, Bilbao, 1980.

${ }_{140}$ Carlos Morales, C. J. de: Carlos V y el crédito de Castilla. El tesorero general Francisco de Vargas y la Hacienda Real entre 1516 y 1524, Madrid, 2000.

${ }^{141}$ Gelabert, J. E.: «La corte de Carlos V y los banqueros italianos en las cuentas de Juan de Adurza, argentier de su majestad (1520-1529)», en "Aspetti della vita economica medievale». Atti del convengo di studi nel $X$ aniversario della morte di Federigo Melis, Firenze, 1985, pp. 515-529.

142 ANDRÉs DíAZ, R. de: El último decenio...

143 Carlos Morales, C. J. de: «Ambiciones y comportamientos de los hombres de negocios. El asentista Melchor de Herrera», en Martínez Millán, J. (Dir.): La Corte de Felipe II, Madrid, 1994, pp. 379-415.

${ }^{144}$ Carlos Morales, C. J. de: «Finanzas y relaciones clientelares en la corte de Felipe II: Juan Fernández de Espinosa, asentista y ministro del Rey», en Política y Religión en la España Moderna. Homenaje al profesor Pérez Villanueva, Madrid, 1996, pp. 221-237.

${ }_{145}$ Ladero Quesada, M. A.: «Actividades de Luis de Santángel en la Corte de Castilla», en Historia, Instituciones, Documentos, no 19 (1992), pp. 231-252. 
ñas ${ }^{146}$ a partir de los cuales podemos conocer numerosos aspectos tocantes a la deuda, crédito o ingresos extraordinarios. Sin embargo, echamos en falta una mayor profundidad en la descripción de las redes sociales urdidas en torno a los tesoreros $^{147}$, lo cual nos llevaría al análisis de sus actividades económicas particulares en conexión con el uso dispensado al oficio. Este hecho resulta clave para apreciar las capacidades de allegar crédito por parte de aquellos oficiales. A su vez, también resulta indispensable combinar el análisis de la actividad en la tesorería con otros aspectos biográficos relacionados tanto con su actividad en la corte como en otros centros de poder. Esta afirmación se puede extender a otros oficios que se encuentran en la completa oscuridad. Por ejemplo, no contamos con muchas noticias sobre la escribanía mayor de rentas más allá de ciertos lugares comunes; tampoco conocemos demasiado de la red de escribanos de partido cuando —en nuestra opinión - constituía un oficio más interesante de lo que se puede pensar en un principio.

Los estudios sobre instituciones no monárquicas también han notado un sustancial avance. Desde los años ochenta, las Cortes de Castilla experimentaron una revalorización en cuanto al papel que ejercían en el sistema político castellano más allá de ciertas interpretaciones procedentes del pensamiento decimonónico. Como es bien sabido, uno de sus principales campos de actuación fue la fiscalidad tanto por la concesión de los servicios como por las negociaciones en torno a los encabezamientos ${ }^{148}$. La renovación, por consiguiente, de los estudios sobre las Cortes ha lanzado a la fiscalidad como un campo fundamental a la hora de observar la relación entre rey y reino, lo cual matiza en profundidad la visión de un sistema político monopolizado por un único poder $^{149}$. En este sentido, la comprensión del sentido o estrategias que tomaron las negociaciones entre ciudades y monarca han avanzado de modo evidente. $\mathrm{Y}$, sin embargo, también existen cuestiones que requieren de un cierto impulso. Por ejemplo, la percepción que poseemos sobre la Diputación en Cortes en el siglo XVI tan sólo viene dada por los magníficos trabajos de Tomás y Va-

146 Martínez Millán, J.: Carlos Morales, C. J. de: «Conversos y elites de poder en Castilla durante la primera mitad del siglo XVI: Rodrigo de Dueñas consejero de Hacienda de Carlos V», en Las tres culturas en la Corona de Castilla y los sefardíes, Salamanca, 1990, pp. 149-163.

${ }_{147}$ Un ejemplo metodológico en ZÉLLER, O.: «Une biographie de fermier general. Réseaux, aprrentissages et strategies», en Histoire, Économie et Societé, no 2 (abril-junio, 1996), pp. 245-280.

${ }^{148}$ Fortea PÉreZ, J. I.: Monarquía y Cortes en la Corona de Castilla. Las ciudades ante la política fiscal de Felipe II, Salamanca, 1990. Para tiempos de los Reyes Católicos, Carretero Zamora, J. M.: Cortes, monarquía, ciudades. Las Cortes de Castilla a comienzos de la época moderna (1476-1515), Madrid, 1988. Para la primera mitad del siglo XVI resulta fundamental HeNDRICKS, C. D.: Charles $V$ and the "Cortes» of Castile. Politics in Renaissance Spain, Cornell University, 1976 (tesis doctoral inédita). Desde una perspectiva más general, Fernández Albaladejo, P.; PARdos, J. A.: «Castilla, territorio sin Cortes (S. XV-XVII), en Revista de las Cortes Generales, no 15 (1988), pp. 113-208.

149 Entre otros, ThOmpson, I. A. A.: «Castile: Absolutism, Constitutionalism, and Liberty», en Hoffman, Ph. T; Norberg, K.: Fiscal crises, liberty and representative government 1450-1789, Stanford, 1994, pp. 181-225. 
liente ${ }^{150}$ y Fortea ${ }^{151}$, gracias a los cuales conocemos la articulación interna de aquella institución. Sin embargo, en nuestra opinión, merecería la pena volver sobre la idea de una Diputación débil y sumisa a los dictados de la Contaduría por varios motivos: en primer lugar, porque presupone que la Contaduría es sinónimo de poder monárquico, cuando su carácter resultaba ser de lo más complejo ${ }^{152}$. Asimismo, en segundo lugar, aquella idea procede de la inclusión de Francisco Garnica en la Diputación, lo que vendría a demostrar la sujeción del organismo que había de velar por la hacienda del reino a los designios de la monarquía. Sin embargo, se ha pasado por alto que Garnica no sólo era contador sino que también llegó a ser regidor de Madrid, circunstancia que refleja su pertenencia a los cuadros del rey y del reino en un magnífico ejemplo de lo que J. J. Ruiz definió como las dos caras de Jano ${ }^{153}$.

El ejemplo de Garnica nos ofrece la oportunidad de adentrarnos en el análisis de las relaciones entre rey y ciudades, lo que nos acerca al tema de la administración territorial. El estado de nuestros conocimientos sobre el entramado de oficios que irán conformando la administración territorial (tesoreros, receptores, arqueros, etc.) continúa siendo un campo prácticamente por explorar ${ }^{154}$. La importancia otorgada a las oligarquías en el control de la fiscalidad ha dado importantes resultados susceptibles de ser aplicados al análisis de los denominados cargos intermedios ${ }^{155}$. Para la primera mitad del siglo XVI la cuestión de

150 Tomás y Valiente, F.: «La Diputación de las Cortes de Castilla (1528-1601)», en Gobierno e Instituciones en la España del Antiguo Régimen, Madrid, 1982, pp. 37-151.

151 Fortea Pérez, J. I.: «Trayectoria de la Diputación en Cortes», en Las Cortes de Castilla y León en la Edad Moderna, Salamanca, 1989, pp. 33-87.

152 Desarrollamos esta idea en nuestra tesis doctoral (Fisco, poder y monarquía en los albores de la modernidad. Castilla, 1504-1525, Madrid, Universidad Complutense, 2004).

153 Ruiz IBÁÑeZ, J. J.: Las dos caras de Jano. Monarquía, ciudad e individuo. Murcia, 1588-1648, Murcia, 1995.

${ }^{154}$ Sobre ello, Dedieu, J. P.; Ruiz RodríGuez, J. I.: «Tres momentos en la historia de la Real Hacienda», en Cuadernos de Historia Moderna, $\mathrm{n}^{\circ} 15$ (1994), pp. 77-99; RuIz RodríGUEZ, J. I.: La Hacienda y la administración territorial de tributos en el siglo XVII. El distrito de los campos de Montiel, Madrid, Universidad Autónoma, 1993 (tesis doctoral inédita).

155 Además de los conocidísimos trabajos de Bonney (The limits of absolutism in ancien regimen France, London, 1995), Tracy (A financial Revolution in the Habsburg Netherlands: Renten and Renteniers in the County of Hollan, Berkeley-Los Angeles-London, 1985) y Collins (Fiscal limits of absolutism. Direct Taxation in Seventeenth-Century France, Barkeley-Los Angeles-London, 1988), nos parecen especialmente sugerentes MUTO, G.: «Tra centro e periferia: la gestione della «Hacienda» nell'Italia Spagnola», en Rassegna Storica Salernitana, no 5, pp. 51-76. Separata; MolHO, A.: «The State and Public Finance: A Hipótesis Based on the History of Late Medieval Florence», en The Origins of the State in Italy, 1300-1600. Suplemento de The Journal of Modern History, vol. 67 (diciembre, 1995), pp. 34-61. Para el caso castellano, además de muchos de los trabajos ya citados, MACKAY, A.: «Hacienda y sociedad en la Castilla bajomedieval», en Estado, hacienda y sociedad en la Historia de España, Valladolid, 1989, pp. 47-78; FONTANA, J.: «Estado y hacienda en el «despotismo ilustrado", en Idem, pp. 125-147; YUN CASAlilla, B.: "Aristocracia, Corona y oligarquías urbanas en Castilla ante el problema fiscal. 1450-1600. (Una reflexión en el largo plazo)», en La gestión del 
las implicaciones de los poderosos en la hacienda ordinaria se ha centrado en el encabezamiento. Desde tiempos de los Reyes Católicos, se negociaron encabezamientos entre rey y ciudades, de modo que la formación del encabezamiento general se ha analizado en un plazo de décadas ${ }^{156}$. Los últimos trabajos tienden a matizar la interpretación tradicional sobre los encabezamientos; a saber, desde Carande, se ha considerado que los encabezamientos constituyeron un verdadero «triunfo» de las ciudades ya que lograrían mantener estables sus encabezamientos en un período de inflación, a cambio, eso sí, de un importante aumento en las cuantías del servicio de Cortes ${ }^{157}$. Esta idea, fundamental durante varias décadas, comienza a equilibrarse desde la visión del encabezamiento general como resultado más complejo que la simple victoria de unos u otros ya que, si bien el reino pagó poco, nunca consiguió que el encabezamiento fuera perpetuo o de mayores plazos. Además, el rey se encontraba muy cómodo con un sistema que le otorgaba seguridad en sus ingresos y en la participación de las oligarquías ${ }^{158}$. Mas no se debe olvidar que las ciudades también se encontraban interesadas en unos esquemas que les permitía obtener beneficios a nivel político y económico, tanto en sus relaciones con el rey como a nivel local ${ }^{159}$. Todo ello incide en la necesidad de continuar asimilando las implicaciones de las oligarquías en los esquemas de aquella fiscalidad, lo cual debe ser entendido tanto en su relación con la Real Hacienda como con otros grupos sociales.

Los importes y rendimientos de alcabalas y tercias cuentan con un estudio reciente basado en los expedientes de hacienda de Simancas ${ }^{160}$. A partir de esta aportación contamos con una visión global de la evolución económica de la hacienda ordinaria para todo el siglo XVI. Asimismo, dicho estudio también

poder. Corona y economías aristocráticas en Castilla (siglos XVI.-XVIII), Madrid, 2002, pp. 73-104 (original publicado en 1991); CASADO ALONSO, H.: «Villes et finances royales. Les stratégies politiques des dirigeants urbains de la Castille septentrionale (1450-1539)», en Menjot, D.; PINOT, J.-L. (Coords.): Enjeux et expressions de la politique municipale (XII $-X X^{e}$ siècles), París, 1997, pp. 193-215. Desde otras perspectivas, Guerrero NAVARreTE, Y.: «Fiscalidad regia y poder municipal», en Estudios en memoria del profesor D. Claudio Sánchez-Albornoz. Monográfico de En La España Medieval, $\mathrm{n}^{\circ} 8$ (1986), t.. I, pp. 481-499.

156 VILLEGAS RUIZ, M.: El encabezamiento: nueva modalidad de recaudación de rentas en la época de Carlos I, Córdoba, 1995.

${ }^{157}$ La tesis se puede seguir, además de en el célebre Carlos $V$ y sus banqueros (tomo II, pp. 221255), en «Gobernantes y gobernados en la hacienda de Castilla (1536-1556)», en Estudios de Historia. 1. Temas de historia de España, Barcelona, 1989, pp. 85-106.

${ }_{158}$ Fortea Pérez, J. I.: «Las Cortes de Castilla en los primeros años del reinado de Carlos V, 1518-1536», en Belenguer CeBriá, E. (Coord.): De la unión de coronas..., vol. I, pp. 411-443.

159 Mathers, C. J.: Relations between the city of Burgos and the Crown, 1506-1556, An Arbor, Michigan, 1973 (tesis doctoral inédita); Alonso GARCía, D: «Carlos V, Madrid y la hacienda real de Castilla», en Revista de Historia Económica, año 21 (2, 2003), pp. 271-295.

160 Zabala Aguirre, P.: Las alcabalas y la hacienda real en Castilla. Siglo XVI, Santander, 2000. Para el período inmediatamente anterior a 1536, AlONSO GARCÍA, D.: «La configuración de lo ordinario en el sistema fiscal de la Monarquía. Una o dos ideas», en Studia Histórica. Historia Moder$n a, \mathrm{n}^{\circ} 21$ (1999), pp. 157-152. 
entra en temas tan importantes como la relación entre Real Hacienda y ciudades o los repartimientos por menor de las rentas encabezadas. Sin embargo, este tipo de disertaciones se debe completar con análisis locales pormenorizados, los cuales, por cierto, no abundan ${ }^{161}$. En la misma línea, existe una punto trascendental que no se ha abordado en todas sus dimensiones: a saber, la implicación (e imbricación) de haciendas municipales y hacienda ordinaria a partir, precisamente, de los entendimientos de las ciudades en encabezamientos, de tal modo que nuestras perspectivas sobre endeudamiento municipal se verían complementadas con análisis transversales de ambas haciendas ${ }^{162}$. Asimismo, las rentas ordinarias también estaban compuestas por tributos como el almojarifazgo o la seda que, más allá de su definición institucional, se encuentran a la espera de estudios a ahonden en cuestiones relativas a su aparato de recaudación, sus rendimientos pormenorizados o los intereses sociales a los que daban lugar ${ }^{163}$.

161 Ya F. Ruiz Martín y A. Domínguez Ortiz llamaron la atención sobre ello. RuIZ MARTín, F.: «Procedimientos crediticios para la recaudación de los tributos fiscales durante los siglos XVI y XVII», en Dinero y crédito. Actas del I Coloquio de Historia Económica, Madrid, 1978, pp. 37-47; Domínguez OrTiz, A.: «Sevilla y la Hacienda de los Austrias: el encabezamiento de alcabalas», en Hacienda Pública Española, no 69 (1981), pp. 67-75. Sobre el encabezamiento contamos con diferentes trabajos. ForTea PÉrez, J. I.: Fiscalidad en Córdoba. Fisco, economía y sociedad: alcabalas y encabezamientos en tierras de Córdoba (1513-1619), Córdoba, 1986; «Los encabezamientos de alcabalas andaluces en la Hacienda real de Castilla (1557-1595)», en Poder político e instituciones en la España Moderna, Alicante, 1992, pp. 15-58; Cremades Griñán, C.: «Notas al sistema de encabezamiento de alcabalas (1536-1556)», en Homenaje al profesor Juan Torrés Fontes, Murcia, 1987, pp. 319-335; Diago Hernando, M.: «La recaudación de las alcabalas en Soria y Ágreda a fines del medievo. Aportación a la historia de la fiscalidad bajomedieval», en Revista de Investigación del Colegio Universitario de Soria, vol. XII, (2, 1992-1994), pp. 99-122; Morales García, C.: El pacto de Sevilla con el Imperio. Presión fiscal, deuda pública y administración en el siglo XVI, Sevilla, 1997; GONZÁLEZ ARCE, J. D.: La fiscalidad del Señorío de Villena en la Baja Edad Media, Albacete, 2002; AsEnjo GonZÁLEZ, M.: «Encabezamientos de alcabalas en Segovia y su episcopalía (1495-1506). Innovaciones fiscales y reacción social», en En la España Medieval, no 20 (1997), pp. 251-280; Solinís EsTALlo, M. A.: La alcabala del rey, 1474-1504. Fiscalidad en el partido de las Cuatro Villas cántabras y las merindades de Campoo y Campos con Palencia, Santander, 2003.

162 Para las primeras décadas del siglo XVI, Sevillano Colom. F.: «Las empresas nacionales de los Reyes Católicos y la aportación económica de la ciudad de Valencia», en Hispania, vol. XIV, $\mathrm{n}^{\mathrm{O}} 57$ (1954), pp. 511-623. Sobre el endeudamiento municipal nos parecen indispensables MARTíNEZ RUIZ, J. I.: Finanzas municipales y crédito público en la España Moderna. La hacienda de la ciudad de Sevilla, 1528-1768, Sevilla, 1992 y PARDOS, J. A.: «Hacienda municipal y constitución de rentas: «censos» y deuda del concejo en Burgos, 1476-1510 ca.», en Anuario de Historia del Derecho Español, t. LIV (1984), pp. 599-612; La bibliografía sobre haciendas municipales es muy extensa, especialmente desde el medievalismo. Sobre ello remitimos a Menjot, D.; SÁnCHEZ MARTínez, M. (Coords.): La fiscalité des villes au Moyen Age (Occident méditerranéen). 2. Les sytstèmes fiscaux, Tolouse, 1996, pp. 516-529; LADERO QueSADA, M. A.: «Las haciendas concejiles en la Corona de Castilla (una visión de conjunto)», en Finanzas y fiscalidad municipal. V Congreso de Estudios Medievales, Ávila, 1997, pp. 7-71.

163 Sobre el almojarifazgo contamos con los trabajos de COlLANTES DE Terán, A.: «Les impôts municipaux indirects ordinariex et extraordinaires de Séville», en MENJOT, D.; SÁNCHEZ MARTínEZ, M. 
La conformación del tesoro real como un cúmulo de estructuras propias implica que cada una de ellas se deba analizar por separado. El servicio de Cortes, en este sentido, es bien conocido gracias los numerosos trabajos de J. M. Carretero, tanto desde un punto de vista cuantitativo ${ }^{164}$ como en relación a los manejos urdidos en torno a la gestión de la fiscalidad extraordinaria ${ }^{165}$. A estos trabajos hay que añadir el interesante análisis de F. J. Romero en torno a la administración de los pedidos en Sevilla durante el siglo XV, demostrando —una vez más - el alto grado de implicación del concejo a partir de la organización de la recaudación, la administración de la justicia en quejas y pleitos así como por la fiscalización de los responsables del cobro ${ }^{166}$. La recaudación de la farda y del servicio en el reino de Granada también cuentan con estudios que nos adentran en la manipulación a la que dio lugar la gestión de aquellas estructuras fiscales ${ }^{167}$. Evidentemente, este tipo de análisis se debe extender a otras zonas para contar con un mayor número de casos que permitan realizar estudios comparativos. En cambio, las contribuciones eclesiásticas no cuentan con una tradición de estudios; esta ausencia resulta sorprendente cuando ya Carande desbrozó el camino. Así, la obra de Goñi Gaztambide continua siendo imprescindible sobre la bula de cruzada ${ }^{168}$, el cual, además de otros títulos recientes $^{169}$, han de constituir el inicio de un nuevo marco investigador a partir de

(Coords.): La fiscalité des villes..., pp. 463-483; GonZÁLEZ ARCE, J. D.: «Las rentas del almojarifazgo de Sevilla», en Studia Histórica. Historia Medieval, no 15 (1997), pp. 209-254. Sobre la influencia del almojarifazgo en la evolución económica andaluza,, PULIDO BUENO, I.: Almojarifazgos y comercio exterior en Andalucía durante la época mercantilista, Huelva, 1993. Sobre la renta de la seda remitimos a nuestro trabajo «Entre Granada y Castilla. La familia Fuente y la hacienda real a comienzos de la Edad Moderna», en Investigaciones Históricas. Época moderna y contemporánea, no 25 (2005), pp. 11-30.

164 CARretero Zamora, J. M.: Cortes, monarquía..., pp. 61-126 y 439-444; Corpus documental de las Cortes de Castilla (1475-1517), Toledo, 1993, pp. 143-192; «Los servicios de Cortes de Castilla en el siglo XVI», en «Tirar con pólvora del rey»..., pp. 15-58.

165 Carretero Zamora, J. M.: «Las oligarquías locales y los mecanismos de exención del servicio de Cortes en la época de Carlos V», en Espacio, tiempo y forma. Historia Moderna, n 11 (1998), pp. 11-37; «Poder municipal, oligarquías y mecanismos de repartimiento y pago de servicios de Cortes en la época de Carlos V», en ARANDA, F. J. (Coord.): Poderes intermedios, poderes interpuestos. Sociedad y oligarquías en la España Moderna, Cuenca, 1999, pp. 109-146.

166 Romero Romero, F. J.: Sevilla y los pedidos de Cortes en el siglo XV, Sevilla, 1997.

167 CASTILlo FernÁNDEZ, J.: «Administración y recaudación de los impuestos para la defensa del reino de Granada: la farda del mar y el servicio ordinario (1501-1516)», en Áreas, no 14 (1992), pp. 67-92; Galán SánCHez, A.; Peinado Santaella, R.: Hacienda regia y población en el Reino de Granada: la geografía morisca del siglo XVI, Granada, 1997, esp. 13-36.

168 GoÑ GaZTambide, J.: Historia de la bula de la Santa Cruzada, Vitoria, 1958.

169 CARPINTERO, L.: «Iglesia y corte castellana en el siglo XVI: contribuciones y tributos», en Hispania Sacra, no 41 (1989), pp. 547-567; CATALÁ MARTíneZ, E.: «El fin de un privilegio: la contribución eclesiástica a la hacienda real (1519-1794)», en Studia Historica. Historia Moderna, no 16 (1997), pp. 177-200; MARcos MARTín, A.: «Tráfico de indulgencias, guerra contra infieles y finanzas regias. La bula de cruzada durante la primera mitad del siglo XVII», en RODRíGUEZ CANCHO, M. (Coord.): Historia y perspectivas de investigación. Estudios en memoria de Ángel Rodríguez Sánchez, 
tres preguntas básicas: la cuantificación del célebre dinero de San Pedro, el desarrollo de la negociación entre monarquía y papado y la puesta en marcha de verdaderas redes de financieros como mecanismo indispensable a la hora de poner en cobro de aquellas rentas ${ }^{170}$.

Por otro lado, el tesoro castellano se caracterizó por su continuado recurso a numerosos ingresos que no procedían de su sistema tributario. Comenzando con la llegada de metal de Indias, tema sobre el que se ha trabajado profusamente desde la célebre obra de Hamilton en relación con la evolución de los precios. Destacar en este sentido los trabajos desarrollados durante los últimos decenios por Morineau ${ }^{171}$, C. Álvarez Nogal ${ }^{172}$, García-Baquero ${ }^{173}$, Martín Acosta ${ }^{174}$ o el reciente estudio de las cuentas de Sancho de Matienzo ${ }^{175}$, los cuales han servido para abrir un interesante debate en torno a la mayor o menor importancia de las remesas americanas en el mantenimiento de la monarquía. A su vez, esta última cuestión se relaciona con otro debate en torno a la mayor o menor rentabilidad económica del imperio americano, cuestión sobre la que giró el XII congreso internacional de historia económica ${ }^{176}$. Por último, en relación con los denominados expedientes fiscales, habríamos de destacar las interesantes aportaciones de A. Marcos Martín sobre la venta de alcabalas ${ }^{177}$.

Badajoz, 2002, pp. 227-236. También aparece información al respecto en PERrone, S. T.: Charles $V$ and the Castilian Assembly of Clergy, University of Wisconsin-Madinson, 1997 (tesis doctoral inédita) y HERMANN, c.: L'Eglise de Espagne sous le patronage royal (1476-1834): essai d'ecclèsiologie politique, Madrid, 1988.

170 Carretero Zamora, J. M.: «La Colectoría en España en Época de Carlos V: Cuentas del nuncio y colector general Giovanni Poggio (1529-1546 )», en Cuadernos de Historia de España, no LXXVIII (2003-2004), pp. 103-135.

${ }_{171}$ MORINEAU, M.: Incroyables gazettes et fabuleux métaux. Les retours des trésors américains d'après les gazettes hollandaises (XVI ${ }^{e}-X V I I^{e}$ siècles), París, 1985.

172 Álvarez Nogal, C.: El crédito de la Monarquía hispánica en el reinado de Felipe IV, Valladolid, 1997; Los banqueros de Felipe IV y los metales preciosos americanos (1621-1665), Madrid, 1997.

173 García-BaQUero GonZÁlez, A.: «Agobios carolinos y tesoros americanos: los secuestros de las remesas particulares en la época del Emperador», en CASTELlanO, J. L.; SÁNCHEZ-Montes, F. (Coord.): Carlos V. Europeísmo..., vol. IV, pp. 309-336.

174 MARTín Acosta, E.: «Las remesas de Indias y la política imperial», en BernAL, A. M. (Ed.): Dinero, moneda..., pp. 405-424.

175 Ladero Quesada, M. A.: El primer oro de América. Los comienzos de la Casa de la Contratación de las Yndias (1503-1511), Madrid, 2002.

176 Yun Casalilla, B.: «The American Empire and the Spanish Economy: An Institutional and Regional Perspective», en Revista de Historia Económica, no 1 (1998), pp. 123-156.

177 Ya MOXÓ («La venta de alcabalas en los reinados de Carlos I y Felipe II», en Anuario de Historia del Derecho Español, t. XLI (1971), pp. 487-554) abrió una senda que, sorprendentemente y salvo casos puntuales, no ha sido continuada. La investigación de A. Marcos apunta a magníficos resultados, tal como demuestra alguno de sus títulos: «<España en almoneda $>$ : enajenaciones por precio de alcabalas y tercias en el siglo XVI», en Las sociedades Ibéricas y el mar a finales del siglo XVI, T. IV, Madrid, 1998, pp. 25-65 
La existencia de multitud de datos sobre alcabalas, servicios, etc. ha posibilitado diversos trabajos que permiten establecer ciertas tendencias en cuanto a la evolución tributaria y la presión fiscal ${ }^{178}$. Sin embargo, debemos continuar aportando estudios primarios que permitan conocer el total de lo recaudado ya que los precios nominales de arrendamientos y encabezamientos no implicaban el total de la recaudación ${ }^{179}$. Esto, a su vez, nos lleva a recordar la importancia de un campo de estudio fundamental en los años sesenta y setenta: las desigualdades contributivas, cuestión que tiene en Domínguez Ortiz uno de sus principales impulsores ${ }^{180}$. Fueron muchas las páginas dedicadas al privilegio fiscal como elemento diferencial de la estructura social del Antiguo Régimen. En cambio, el ascenso de las oligarquías como sujeto de estudio parece haber orillado esta cuestión cuando se trataba de un hecho fundamental de aquel régimen fiscal. Esperemos que la reciente e interesante obra de R. Valladares sobre los proyectos del medio general en tiempos de Felipe IV sirva para rescatar una línea de investigación que siempre nos debe recordar que la característica más importante de aquel fisco fue el privilegio, al menos desde el punto de vista de su historia social ${ }^{181}$.

Las consecuencias sociales de la fiscalidad constituyen otro campo de estudio apasionante. Como viene demostrando L. Rooth ${ }^{182}$, los dispendios realizados por las monarquías constituyeron un medio de redistribución de capital por el que se podía favorecer a grupos determinados. Los territorios de la monarquía hispánica, en general, siguieron esta máxima aun cuando los modelos fis-

178 Además de estudios generales (Ulloa, Gelabert, etc.), BILBAO, L. $\mathrm{M}^{\mathrm{a}}$.: «Ensayo de reconstrucción histórica de la presión fiscal en Castilla durante el siglo XVI», en Haciendas forales y hacienda real. Homenaje a D. Miguel Artola y D. Felipe Ruiz Martín, Bilbao, 1991, pp. 63-79.

179 Gómez Álvarez, U.: «Teoría de la medición indirecta de las variables económicas: el caso de la alcabala», en Historia Moderna. Actas de las II Jornadas de Metodología y Didáctica de la Historia, Cáceres, 1983, pp. 233-249.; Revisión histórica de la presión fiscal castellana (siglos XVI-XVIII), Oviedo, 1996 .

180 Domínguez OrTiZ, A.: «La desigualdad contributiva en Castilla en el siglo XVII», en Anuario de Historia del Derecho Español, $\mathrm{n}^{\circ} 21$ (1951), pp. 1222-1271; Política fiscal y cambio social en la España del siglo XVII, Madrid, 1984.

181 Valladares, R.: Banqueros y vasallos. Felipe IV y el medio general, Cuenca, 2002. En este sentido, también resulta interesante la implicación de lo político, social y económico propuesta por Guerrero NAVArrete, Y.: «Impuestos y contribuyentes en los concejos de la meseta norte», en Finanzas y fiscalidad municipal..., pp. 353-394 y Diago HERNANDO, M.: «La recaudación...». Se pueden extraer algunas conclusiones significativas en ROMERo MARTínEZ, A.: «Proceso recaudatorio y mecanismos fiscales en los concejos de la Corona de Castilla», en Anuario de Estudios Medievales, $\mathrm{n}^{\mathrm{o}} 22$ (1992), pp. 739-766.

182 RoOT, L, H.: «The Redistributive Role of Government: Economic Regulation in Old Régimen France and England», en Comparatives Studies in Society and History, vol. 33 (2, 1991), pp. 338-369; The Fountain of Privilege. Political foundations of Markets in Old Regime France and England, Berkeley-Los Angeles-London, 1994. En la misma línea, Pezzolo, L.: «Government Debts and Trust. French Kings and Roman Popes as Borrowers», en Rivista di Storia Economica, no 3 (1999), pp. 233-261. 
cales por los que las oligarquías entraban en el sistema eran diferentes ${ }^{183}$. La idea, en nuestra opinión, resulta fundamental para redefinir unos sistemas fiscales establecidos a partir de una idea tradicional de deuda como resultante de un pretendido desequilibrio entre ingreso y gasto ${ }^{184}$. Cierto es que aquel proceso poseía algunas características diferentes al modelo castellano, pero no deja de resultar paradójico que se haya juzgado con dureza al modelo castellano por el peso de la deuda cuando otros autores (Dickson, Tracy, Roseveare) han señalado, precisamente, que fue ésta y la subsiguiente creación de mercados secundarios los motores de la modernización de los sistemas fiscales a partir de la denominada «revolución financiera» ${ }^{185}$. En cualquier caso, con una revisión del concepto de deuda estamos revalorizando el gasto como un tema clave a la hora de abordar la evolución fiscal y política de la monarquía, si bien es una línea de futuro que sólo ha sido esbozada ${ }^{186}$. Los estudios sobre juros, salvo excepciones que no suelen proceder de la historia fiscal, no han atendido a su sociología o utilización en un hipotético mercado secundario ${ }^{187}$. Y esta cuestión posee una importancia capital a la hora de abordar el sistema financiero castellano. Mención aparte merece un tema puntual para el presente trabajo: nos referimos a la declaratoria de juros

183 SABAtini, G.: «Notas sobre la fiscalidad napolitana en la época de Fernando el Católico», en El tratado de Tordesillas..., vol. III, pp. 1805-1815; HernándeZ, B.: Fiscalidad de Reinos y Deuda Pública en la Monarquía Hispánica del siglo XVI, Córdoba, 2001.

${ }_{184}$ CARretero Zamora, J .M.: «Fiscalidad parlamentaria y deuda imperial», en GARCía GarCíA, B.: El Imperio de Carlos V. Procesos de agregación y conflictos, Madrid, 2000, pp. 157-184; «Liquidez, deuda y obtención de recursos extraordinarios (en torno a los servicios de Cortes en época de Carlos V)», en MARTínez MilláN, J (Coord.): Carlos $V$ y la quiebra del bumanismo político en Europa (1530-1558), vol. IV, Madrid, 2001, pp. 443-461.

${ }_{185}$ Una crítica a dicha interpretación en CARLOS MORALES, C. J. de: «¿Una revolución financiera en tiempos de Felipe II? Dimensiones y evolución de los fundamentos de la Hacienda Real de Castilla, 1556-1598», en Belenguer Cebriá, E.: Felipe II y el Mediterráneo, vol., I, Madrid, 1999, pp. 473504. Los últimos años han sido pródigos en trabajos que proponen la idea de evolución fiscal antes que de revolución financiera. Vid BONNEY, R,; ORMROD, W. M.: «Introduction», en ORMROD, W. M. et alii: Crises, Revolutions and Self-Sustained Growth. Essays in European Fiscal History, 1130-1830, Stanford, 1999, pp. 1-21. Una reciente revisión de las conocidas teorías de Tracy sobre la «revolución financiera» en los Países Bajos en FRITSCHY, W.: «A «financial revolution» reconsidered: public finance in Holland during the Dutch Revolt, 1568-1648», en The Economic History Review, vol. LVI, nº 1 (2003), pp. 5789. Los precedentes medievales de la «revolución financiera» han sido puestos de manifiesto por MUNRO, J. H.: «The Medieval Origins of the Financial Revolution: Usury, Rentes, and Negociability», en The International History Review, vol. XXV (3, 2003), pp. 505-562.

186 HernÁndeZ, B.: Fiscalidad...; «Real Hacienda y fiscalidad de reinos. Las finanzas catalanas en el Imperio de Carlos V», en MARTínez Millán, J (Coord.): Carlos V y la quiebra..., vol. IV, pp. 473-493; Thompson, I. A.A.: «Taxation, Military Spending and the Domestic Economy in Castile in the Later Sixteenth Century», en War and Society in Habsburg Spain, Londres, 1992, pp. 1-21.

187 Además de los trabajos clásicos de Castillo Pintado, ToBOso SÁnCHEZ, P.: La deuda pública castellana durante el Antiguo Régimen (Juros), Madrid, 1987. Las implicaciones de los grupos oligárquicos en el desarrollo de la deuda consolidada en VeSETH, M.: Mountains of Debt. Crisis and Change in Renaissance Florence, Victorian Britain, and Postwar America, New York-Oxford, 1990. 
de 1480 , a cuyo tratamiento descriptivo de Matilla Tascón ${ }^{188}$ respondió Halizcer ofreciendo una interpretación mucho más matizada ${ }^{189}$.

Por último, ligado al tema de la deuda encontramos un mundo de banqueros, mercaderes o arrendadores. La Real Hacienda debía negociar constantemente el suministro de crédito por parte de los diferentes grupos de financieros desde unas posiciones definidas ${ }^{190}$, si bien se ha prestado especial atención a la negociación en los momentos de suspensión de pagos y medios generales ${ }^{191}$. En cualquier caso, el universo de la banca — de los banqueros — supone uno de los campos más prolíficos de la historia económica, especialmente a partir de los trabajos pioneros de R. López, J. Heers, R. Pike, Lapeyre, el propio F. Ruiz Martín, etc. De este modo, tanto la gran banca alemana como los entramados genoveses cuentan con multitud de títulos que demuestran las redes sociales articuladas en torno a las diferentes familias que dan nombre a aquella banca, en especial en las ciudades andaluzas ${ }^{192}$. Y, sin embargo, nuestro nivel de conocimientos en torno a la presencia genovesa en ciudades de la meseta (Vallado-

188 Matilla Tascón, A.: Declaratoria de los Reyes Católicos sobre reducción de juros y otras mercedes, Madrid, 1952.

189 HalizCER, S.: «The Castilian Aristocracy and the mercedes Reform of 1478-1482», en The Hispanic American Historical Review, vol. 55 (1975), pp. 448-467.

190 Sobre el asunto, SANZ AYÁN, C.: Los banqueros de Carlos II, Valladolid, 1989; ÁlvarEZ NoGAL, C.: «La estrategia de la Real Hacienda en la negociación del crédito de los Austrias», en BERNAL, A. M.: Dinero, moneda..., pp. 439-456. Para tiempos del Emperador, CARLOS MORALES, C. J. de: «Carlos V en una encrucijada financiera: las relaciones entre los mercaderes-banqueros alemanes, genoveses y españoles en los asientos de 1529-1533", en MARTínez Millán, J. (Coord.): Carlos V y la quiebra..., vol. IV, pp. 405-429; PACINI, A.: La Genova di Andrea Doria nell'Impero di Carlo V, Firenze, 1999.

191 Felloni, G.: «Asientos, juros y ferias de cambio desde el observatorio genovés (15411675)», en Dinero y crédito..., pp. 335-359; NERI, E.: Uomini d'affari e di governo tra Genova e Madrid (secoli XVI e XVII), Milán, 1989, pp. 82-124; CONKLIN, J.: The theory sovereign debt and Spain under Philiph II, Madrid, 1996; LoveTT, A. W.: «The Castilian bankruptcy of 1575», en The Historical Journal, $\mathrm{n}^{\circ} 23$ (3, 1980), pp. 899-911; «The general settlement of 1577: an aspect of Spanish finances in the Early modern period», en The Historical Journal, $\mathrm{n}^{\circ} 25$ (1, 1982), pp. 1-22; MUTO, G.: « $<$ Decretos $>$ e $<$ medios generales $>$ : la gestione delle crisis finanziare nell'Italia spagnola», en Maddalena, A. de; KellenbenZ, H.: La repubblica internazionale del denaro tra XV e XVII secolo, Bolonia, 1986, pp. 275-332; CANOSA, R.: Banchieri genovesi e sovrani spagnoli tra Cinquecentoe Seicento, Roma, 1998; SANZ AYÁN, C.: «La estrategia de la Monarquía en la suspensión de pagos del 96 y su «medio general», en Las sociedades Ibéricas..., vol. II, pp. 81-95. Recientemente contamos con un ensayo de biografía familiar de los Centurión en PULIDO BUENO, I.: La familia genovesa Centurión (mercaderes, diplomáticos y hombres de armas), al servicio de España, 1380-1680, Huelva, 2004.

192 Kellenbenz, H.: Los Fugger en España y Portugal hasta 1560, Salamanca, 2000. Sobre la banca genovesa remitimos a OTTE, E.: «Il ruolo dei Genovesi nella Spagna del XV e XVI secolo», en Maddalena, A. de; Kellenbenz, H.: La repubblica internazionale..., pp. 17-56; SANZ AyÁN, C.: «La presencia del capitalismo cosmopolita durante el reinado de los Reyes Católicos: claves para una interpretación», en El Tratado de Tordesillas y su época, vol, I, Madrid, 1995 pp. 467-477; IGUAL Luis, D.; Navarro, G.: «Los genoveses en España en el tránsito del siglo XV al XVI», en Historia. Instituciones. Documentos, nº 24 (1997), pp. 261-332, con un importante listado bibliográfico. 
lid, Medina, etc.) es muy inferior al de los núcleos del sur peninsular ${ }^{193}$. Además, también echamos en falta una mayor relación de las actividades bancarias o mercantiles particulares con sus estrategias o actitudes con la Real Hacienda cuando ambas actividades constituían las dos caras de la misma moneda194. Para ello resulta imprescindible un acercamiento a los grupos de mercaderes castellanos, campo en el que contamos con una tradición de décadas a partir de Carande y M. Basas ${ }^{195}$. Desde aquí se han estudiado los grupos mercaderes de diversas ciudades (Burgos, Sevilla, Valencia, Barcelona, etc.). Pero se debe continuar con el estudio de las comunidades de los distintos núcleos urbanos, los cuales pueden combinar esta perspectiva con estudios biográficos -individuales o familiares - que permitan una diversificación de puntos de vista ${ }^{196}$. A su vez, tal como se viene haciendo en los últimos años, se debe insistir en las relaciones de los grupos de mercaderes con el nivel político ${ }^{197}$. Y también resultaría altamente recomendable continuar con una de las líneas de estudio más fructífera de los últimos años, como es el establecimiento de redes mercantiles entre Castilla y diversas zonas del norte de Europa ${ }^{198}$. El modelo sería perfectamente extensible al ámbito italiano, especialmente porque el número de pu-

193 Como excepción contamos con el trabajo de Diago Hernando, M.: «El cardenal de San Jorge y los hombres de negocios genoveses en Cuenca durante el reinado de los Reyes Católicos», en Espacio, Tiempo y Forma. Historia Medieval, vol. 10 (1997), pp. 137-155.

${ }^{194}$ Un ejemplo de implicación de ambos aspectos en ALONSO GARCíA, D.: «Los Fornari y las rentas de Orán a comienzos del siglo XVI. Financiación del rey y negocio familiar», en Los extranjeros en la España Moderna. Actas del I Coloquio Internacional, t. II, Málaga, 2003, pp. 101-112.

195 BASAS FERNÁNDEZ, M.: «Mercaderes burgaleses en el siglo XVI», en Boletín de la Institución Fernán González, no 126 (1954), pp. 55-67 y no 127 (1954), pp. 156-169; El Consulado de Burgos en el siglo XVI, Burgos, 1994 ( $1^{\mathrm{a}}$ ed., 1963); «Banqueros burgaleses del siglo XVI», en Boletín de la Institución Fernán González, no 163 (1964), pp. 314-332. En la misma línea, cabe recordar el trabajo pionero de F. Ruiz Martín sobre los grupos bancarios en Castilla durante el Antiguo Régimen («La banca en España hasta 1782», en El banco de España. Una historia económica, Madrid, 1970, pp. 1-196.

196 Ródenas Vilar, R.: Vida cotidiana Y Negocio En La Segovia Del Siglo De Oro. El Mercader Juan De Cuéllar, Valladolid, 1990; CAUnedo DEL Potro, B.: «Operaciones comerciales del grupo familiar Castro a fines del siglo XV», en Estudios en memoria del profesor D. Claudio Sánchez-Albornoz. Monográfico de En La España Medieval, no 8 (1986), pp. 289-298. Asimismo, conviene señalar los avances que se están realizando a partir de biografías de arbitristas: DUBET, A.: Réformer les finances espagnoles au siècle d'or. Valle de la Cerda, Clermont-Ferrand, 2000; ARANDA, F. J.: Jerónimo de Cevallos: un hombre grave para la República. Vida y obra de un hidalgo del saber en la España del siglo de oro, Córdoba, 2001.

197 Esta cuestión resulta un lugar común en la historiografía sobre las ciudades italianas. Vid, SPUFFORD, P.: «The role of Entrepeneurs in State Formation in Late Medieval Europe», en Poteri economici e poteri politici. Secc. XIII-XVIII, Prato, 1998, pp. 483-500. Para el caso castellano, EDWARDS, J. H.: «Oligarchy and Merchant Capitalism in Lower Andalusía under the Catholic Kings: the Case of Cordoba and Jerez de la Frontera», en Historia. Instituciones. Documentos, $\mathrm{n}^{\circ} 4$ (1977), pp. 11-33; Narbona, R.; Cruselles, E.: «Espacios económicos y sociedad política en la Valencia del siglo XV», en NARBONA, R. (Coord.): Oligarquías políticas..., pp. 193-214.

198 Como acercamiento a este punto remitimos a CaSADO Alonso, H.: El triunfo de Mercurio. La Presencia Castellana en Europa (Siglos XV y XVI), Burgos, 2003. 
blicaciones al respecto no se corresponde con la importancia política y económica de dicho espacio ${ }^{199}$.

Por otro lado, desde un punto de vista fiscal, se debe poner en común el análisis de la banca o mercaderes castellanos con otra de sus actividades preferidas: el arrendamiento de rentas. En este sentido, la escasez de conocimientos sobre la figura del arrendador resulta alarmante ya que, exceptuando trabajos determinados sobre compañías o grupos concretos (véase los judíos), no contamos con una visión nítida en torno a lo que suponía aquel sistema de recaudación en relación con las implicaciones sociales, económicas y políticas de sus protagonistas. Sólo durante los últimos años comienza a abrirse paso esta perspectiva a partir de trabajos que, en cualquier caso, tienden a remitir a casos particulares con el consiguiente riesgo de atomización de una cuestión que podría ser tratada con perspectivas más amplias ${ }^{200}$. Metodológicamente, incluso,

199 Sobre las relaciones comerciales entre Castila e Italia contamos con DINI, B.: «Mercaderes españoles en Florencia (1480-1530)», en Actas del V Centenario del Consulado de Burgos, vol. I, Burgos, 1994, pp. 323-347; VAQUERO PIÑEIRO, M.: «Relaciones entre las villas cántabras de la costa y la península italiana en los siglos XIV y XV. Datos para su estudio», en El fuero de Santander y su época, Santander, 1989, pp. 307-315. «Una realità nazionale composita: comunitè e chiese «spagnole» a Roma», en GensinI, S. (a cura di): Roma capitale (1447-1527), Pisa, 1994, pp. 473-491; "Mercaderes catalanes y valencianos en el Consulado de Roma», en NARBONA, R. (coord..): Oligarquías políticas y elites económicas en las ciudades bajomedievales (siglos XIV-XVI), Valencia, 1999, pp. 151-172; SERIO, A.: «Algunes consideracions sobre la presencia catalanoaragonesa a Roma entre el final del Quatrocento i el principi del Cinquecento (1492-1522)», en Butlletí de la Societat Catalana d'Estudis Històrics, vol. XIV (2003), pp. 69-96.

Las relaciones comerciales entre Castilla y Roma también han llamado la atención de DANDELET, T.: La Roma española (1500-1700), Barcelona, 2002.

${ }^{200}$ Como trabajos monográficos contamos con MACKAY, A.: «Documentos para la historia de los financieros castellanos de la Baja Edad Media I: una «información» del 23 de septiembre de 1466», en Historia. Instituciones. Documentos, no 5 (1978), pp. 321-327; LlanOs MARTíNeZ, $\mathrm{M}^{\mathrm{a}}$ de los: «Rentas reales en los comienzos del siglo XV murciano. Arrendadores y recaudadores», en Mvrgetana, vol. LIX (1980), pp. 37-56; COLlantes DE TerÁn, A.: «Los fiadores en la hacienda concejil sevillana bajomedieval», en Mayurqa, $\mathrm{n}^{\circ} 22$ (1989), pp. 191-197; DiAGo HeRnANDO, M.: «Arrendadores arandinos al servicio de los Reyes Católicos», en Historia. Instituciones. Documentos, $\mathrm{n}^{\circ}$ 18 (1991), pp. 71-95; «Los hombres de negocios en la ciudad de Soria durante el siglo XVI», en Hispania, vol. LX/2, $\mathrm{n}^{\circ} 205$ (2000), pp. 479-514;; CASADO AlONSO, H.: "Comercio, crédito y finanzas públicas en Castilla en la época de los Reyes Católicos», en BernaL, A. M. (Coord.): Dinero, moneda..., pp. 135-156; CARretero ZAMORA, J. M.: «Los arrendadores de la Hacienda de Castilla a comienzos del siglo XVI (1517-1525)», en Studia Histórica. Historia Moderna, no 21 (1999), pp. 153-190. Alonso García, D.: «Un mundo de financieros. La Hacienda Real de Castilla y sus arrendadores en las postrimerías del reinado», en Congreso Internacional Isabel la Católica y su época (en prensa). Sobre arrendadores judíos, CARRETE PARRONDO, C.: «La hacienda castellana de Rabbi Meir Relamed», en Sefarad, no 37 (1977), pp. 339-349; «R. Abraham Seneor (Fernán Pérez Coronel): Conjeturas tradicionales y realidad documental», en Sefarad, año XLVI (1986), pp. 111-121; ÁLVAREZ GARCía, C.: «Los judíos y la hacienda real de Castilla bajo el reinado de los Reyes Católicos. Una compañía de arrendadores de rentas reales», en Las tres culturas..., 87-121; LADERO QUESADA, M. A.: «Los judíos castellanos del siglo XV en el arrendamiento de impuestos reales», en El siglo XV 
se podrían importar diversas línea de análisis desarrolladas en torno a un crédito particular cuya razón de ser no sólo era económico ${ }^{201}$.

$$
* \quad * \quad *
$$

En definitiva y como conclusión personal, la historiografía sobre comienzos del siglo XVI en sus vertientes políticas y financiera goza de una buena salud general si lo comparamos que la producción existente hace unas cuantas décadas. Sin embargo, esto no debe inducir a la autocomplacencia ya que existen líneas de investigación manifiestamente mejorables donde, incluso, podemos hallar verdaderos páramos que urgen ser investigados. La aseveración se hace especialmente evidente en lo tocante a los mecanismos de socialización referidos a la práctica fiscal y a sus modelos de gestión. Esto nos llevaría al inexplorado campo de los discursos fiscales, la propaganda, la transmisión y circulación de información en la hacienda, la cultura fiscal etc. donde no sobraría la introducción de conceptos antropológicos y culturales. Todo ello en pos de un pasado que necesita ser revisado constantemente para construir una historia, un discurso, que pueda ser inteligible ante los ojos de un presente siempre cambiante; factor consustancial en la vitalidad de una Clío cuyo sustento fundamental mana de la crítica y la reflexión.

en Castilla..., pp. 143-167; «La receptoría y pagaduría general de la Hacienda regia castellana entre 1491 y 1494 (De Rabí Meír Melamed a Fernán Núñez Coronel), en En la España Medieval, no 25 (2002); pp. 425-506; MORENO KOCH, Y.: «Diez años de actividad económica en el reinado de los Reyes Católicos. Rabí Meir Melamed (Fernán Núñez Coronel)», en CARrete, C.; MeYuhas, A.: Creencias y culturas. Cristiano, judíos y musulmanes en la España Medieval, Salamanca, 1998, pp.159168; Parello, V.: «Un oligarca converso de la Mancha en el siglo XVI. El caso de Marcos de Madrid», en Sefarad, año 58 (2, 1998), pp. 315-337. Una perspectiva institucional del arrendamiento en Solinís Estalló, M. A.: "Notas sobre el arrendamiento de la alcabala a través de los cuadernos de 1462 y 1484», en Anuario de Estudios Medievales, nº 22 (1992), pp. 803-820.

${ }^{201}$ Clavero, B.: Antidora. Antropología católica de la económica moderna, Milán, 1991. Una magnífica reseña a este libro en Moutoukias, Z.: «Peut-on faire l'économie d'une économie politique? (note critique), en Annales. Histoire. Sciences Sociales, n 6 (noviembre-diciembre, 2001), pp. 11111128. También, MULDREw, C.: The Economy of Obligation. The Culture of Credit and Social Relations in Early Modern England, New York, 1998. El funcionamiento de los mecanismos de crédito en Castilla se puede seguir en la tesis de F. H. Abed-Al Hussein, publicada en diferentes capítulos en LORENZO, E.: Historia de Medina del Campo y su tierra, vol. II., Valladolid, 1986. Sobre las implicaciones sociales del crédito a principios del siglo XVI, GARCía SANZ, A.: «El crédito a principios del siglo XVI en una ciudad de Castilla: la nobleza urbana como financiadora del comercio y de la industria en Segovia, 1503-1508», en Studia Histórica. Historia Moderna, vol. V (1987), pp. 77-89. En relación con América, Bernal, A. M.: La financiación de la Carrera de Indias (1492-1824). Dinero y crédito en el comercio colonial español con América, Sevilla, 1992. Sobre los sistemas internacionales de ferias remitimos a Monnaie privée et pouvoir des princes, París, 1986. 